NBER WORKING PAPER SERIES

\title{
THE IMPACT OF TRADE ON INTRA-INDUSTRY REALLOCATIONS AND AGGREGATE INDUSTRY PRODUCTIVITY
}

\author{
Marc J. Melitz \\ Working Paper 8881 \\ http://www.nber.org/papers/w8881 \\ NATIONAL BUREAU OF ECONOMIC RESEARCH \\ 1050 Massachusetts Avenue \\ Cambridge, MA 02138 \\ April 2002
}

The author thanks, without implicating, Alan Deardor, Jim Levinsohn, and Elhanan Helpman for helpful comments and discussions. Funding from the Alfred P. Sloan Foundation is gratefully acknowledged. The views expressed herein are those of the author and not necessarily those of the National Bureau of Economic Research.

(C) 2002 by Marc J. Melitz. All rights reserved. Short sections of text, not to exceed two paragraphs, may be quoted without explicit permission provided that full credit, including $\mathbb{C}$ notice, is given to the source. 
The Impact of Trade on Intra-Industry Reallocations and Aggregate Industry Productivity Marc J. Melitz

NBER Working Paper No. 8881

April 2002

JEL No. F1

\begin{abstract}
This paper builds a dynamic industry model with heterogeneous firms that explains why international trade induces reallocations of resources among firms in an industry. The paper shows how the exposure to trade will induce only the more productive firms to enter the export market (while some less productive firms continue to produce only for the domestic market) and will simultaneously force the least productive firms to exit. It then shows how further increases in the industry's exposure to trade lead to additional inter-firm reallocations towards more productive firms. These phenomena have been empirically documented but can not be explained by current general equilibrium trade models, because they rely on a representative firm framework. The paper also shows how the aggregate industry productivity growth generated by the reallocations contributes to a welfare gain, thus highlighting a benefit from trade that has not been examined theoretically before. The paper adapts Hopenhayn's (1992a) dynamic industry model to monopolistic competition in a general equilibrium setting. In so doing, the paper provides an extension of Krugman's (1980) trade model that incorporates firm level productivity differences. Firms with different productivity levels coexist in an industry because each firm faces initial uncertainty concerning its productivity before making an irreversible investment to enter the industry. Entry into the export market is also costly, but the firm's decision to export occurs after it gains knowledge of its productivity.
\end{abstract}

Mark J. Melitz

Department of Economics

Littauer Center

Harvard University

Cambridge, MA 02138

and NBER

mmelitz@harvard.edu 


\section{Introduction}

Recent empirical research using longitudinal plant or firm-level data in several countries has overwhelmingly substantiated the existence of large and persistent productivity differences among establishments in the same narrowly defined industries. Foster, Haltiwanger and Krizan (1998) summarize this research by concluding that “... within sector differences dwarf between sector differences in behavior." In related work, Haltiwanger (1997, Table 1) reports that 4-digit industry effects explain less than 10 percent of the overall variation in the growth rates of output, employment, capital stocks, and productivity across establishments in the U.S. from 1977 to 1987. Complementing this evidence on the extent of within sector heterogeneity, other studies have shown that the bulk of resource reallocations across firms remains internal to the specific sector. Davis and Haltiwanger (1999) summarize this evidence for the U.S. and report that less than 1 in 10 job reallocations reflect employment shifts across sectors. Levinsohn (1999) reports similar numbers for most industries in Chile following wide-reaching trade liberalization. Evidence reported in Roberts and Tybout (1996) and Davis and Haltiwanger (1999) confirms that these patterns are not specific to the U.S. and that substantial within sector reallocations between heterogeneous firms are also prevalent in developing countries.

If these large intra-industry reallocations were unrelated to the heterogeneous characteristics of firms, then their separate existence would not necessarily make them important determining factors of industry performance. On the other hand, if the reallocations are related to firm characteristics, then the nature of the link between the two significantly affects several important aspects of industry performance. Although the analysis of this link between firm characteristics and industry evolution is an ongoing research program, enough evidence has been collected to demonstrate its existence and relevance for industry performance. The main firm characteristic found to be empirically linked to intra-industry reallocations is firm productivity. ${ }^{1}$ The strongest evidence of this link pertains to firm entry and exit decisions. Productivity differences between entering and exiting firms significantly contribute to aggregate industry productivity changes over time. Additionally, a large number of studies have documented a strong correlation between firm exit and low productivity (firm age is also correlated with exit: younger firms have disproportionately high failure rates). Finally, some studies have also found evidence that reallocations unrelated to entry and exit contribute to

\footnotetext{
${ }^{1}$ Firm age and capital vintage are other important explanatory characteristics that have been highlighted in some studies, although their impact may be limited to their effect on productivity.
} 
industry productivity growth by redistributing market shares among incumbent firms. ${ }^{2}$ A similar reallocation process has also been studied at a higher level of aggregation: Basu and Fernald (1997) find that U.S. aggregate productivity changes across the business cycle are partly driven by expenditure reallocations across sectors with different average productivity levels. The inherent inability of representative firm industry models to explain the contribution of reallocations to industry performance has prompted the development of a theoretical literature of industry dynamics that emphasizes the role of firm level heterogeneity. This literature, along with the previously mentioned empirical evidence, is reviewed in Foster, Haltiwanger and Krizan (1998) and Tybout (2002).

This paper adapts one of these recent industry models with heterogeneous firms in order to analyze the role of international trade as a catalyst for inter-firm reallocations within an industry. It then describes how these reallocations affect both industry performance and welfare. The business press often assumes the existence of this catalyst role of trade when describing how exposure to trade has both enhanced the growth opportunities of some firms while simultaneously contributing to the downfall or "downsizing" of other firms in the same industry. Similarly, protection from trade is reported to shelter inefficient firms. Rigorous empirical work has recently corroborated this anecdotal evidence. Bernard and Jensen (1999a) (for the U.S.), Aw, Chung and Roberts (2000) (for Taiwan), and Clerides, Lach and Tybout (1998) (for Colombia, Mexico, and Morocco) all find evidence that the causation of the correlation between firm productivity and export status runs from the former to the latter: more productive firms self-select into the export market. Aw, Chung and Roberts (2000) also find evidence suggesting that exposure to trade forces the least productive firms to exit the industry (firms with higher productivity levels relative to the incumbent average exit after the exposure to trade). Both of these selection effects (into the export market and out of the industry) obviously reallocate market shares from less productive firms (who exit) to more productive ones (who export) and therefore contribute to industry productivity growth. ${ }^{3}$ Pavcnik (2002) directly looks at the contribution of market share reallocations to sectoral productivity growth following trade liberalization in Chile. She finds that these reallocations significantly contribute to productivity growth in the tradable sectors. In a related study, Bernard and Jensen (1999b) find that within-sector market share reallocations towards more productive exporting plants accounts

\footnotetext{
${ }^{2}$ The importance of this phenomenon varies across studies and is cyclically sensitive (see Foster, Haltiwanger and Krizan (1998))

${ }^{3}$ Forces other than trade also affect the reallocation of resources within an industry. Olley and Pakes (1996) find that deregulation in the U.S. telecommunications industry increased productivity predominantly through this channel rather than through intra-firm productivity gains.
} 
for $20 \%$ of U.S. manufacturing productivity growth.

By relying on a representative firm framework (at least at the level of the industry), general equilibrium trade models have largely ignored these intra-industry reallocations and focused instead on other consequences of trade, such as inter-industry reallocations or phenomena affecting all firms in similar ways. ${ }^{4}$ This paper attempts to fill this gap by providing a general equilibrium model with heterogeneous firms that explains how trade induces these selection effects and intra-industry reallocations. This model shows how exposure to trade will induce only the more productive firms to enter the export markets (while some less productive firms continue to produce only for the domestic market) and will simultaneously force the least productive firms to exit. The paper then shows how further increases in the industry's exposure to trade (driven either by trade liberalization or the addition of new trading partners) lead to additional inter-firm reallocations towards more productive firms. The model thus explains how trade can generate industry productivity growth without necessarily affecting intra-firm efficiency. It also provides a theoretical foundation for the recent empirical findings described above and rigorously shows how trade can contribute to the Darwinian evolution of industries - forcing the least efficient firms to contract or exit while promoting the growth and success of the more efficient ones.

Another recent paper by Bernard, Eaton, Jenson and Kortum (2000) also introduces firm-level heterogeneity into a model of trade by adapting a Ricardian model to firm-specific comparative advantage. Both papers predict the same basic kinds of trade-induced reallocations, although the channels and motivations behind these reallocations vary. In addition, Bernard et al. (2000) show how their model can be calibrated to provide a good fit to a combination of micro and macro US data patterns. However, subsequent work by Brooks (2001) has shown that this feature is not robust across countries. The current paper relies on the previously documented empirical micro patterns and focuses on the theoretical explanations and motivations behind these patterns.

\footnotetext{
${ }^{4}$ This last category includes models that assume a direct link between trade and firm level efficiency. In these models, exposure to trade typically increases the efficiency level of all firms through a variety of channels: learning effects, increased scale of production, increased innovation, higher quality or diversity of intermediate inputs, reduction of agency problems between owners and managers. Clerides, Lach and Tybout (1998) and Bernard and Jensen (1999a) specifically test whether new exporting firms become more efficient. Neither of these studies finds evidence supporting this hypothesis. Tybout and Westbrook (1995) test and reject the hypothesis that increased productivity in Mexico's growing export industries was driven by increases in the scale of plant production.
} 


\section{Model Background}

Incorporating heterogeneity in a dynamic industry setting, where forward looking firms make entry and export decisions, necessarily increases the technical complexity of this model vis-a-vis its representative firm counterparts. In order to reduce this additional complexity, I abstract from some of the firm-level dynamic stochastic processes that are typically modeled in the recent industry dynamics literature, while preserving the necessary components that explain how certain characteristics of industries shape their endogenous composition with heterogeneous firms. The main forces explaining the impact of trade on an industry are nevertheless quite intuitive. The opening of new export markets exclusively benefits the more efficient firms, as entry into these markets is costly and can only be afforded by the more efficient firms (who earn higher profits).

This model builds upon Krugman's (1980) analysis of trade in the presence of product differentiation, increasing returns, and monopolistic competition, by incorporating firm level productivity differences. Given the differentiation of goods, these productivity differences may reflect more than just cost differences among products yielding the same utility. Higher productivity can also be interpreted as producing a better product (generating higher utility) at equal cost. The model draws heavily from Hopenhayn's $(1992 a, 1992 b)$ work on firm and industry productivity dynamics to explain the endogenous selection of heterogeneous firms in an industry. Instead of assuming some immutable and innate ordering of firms from most to least productive, Hopenhayn derives the equilibrium distribution of firm productivity from the profit maximizing decisions of initially identical firms who are uncertain of their initial and future productivity. ${ }^{5}$ This paper adapts his model to a monopolistically competitive industry (Hopenhayn only considers competitive firms) in a general equilibrium setting. ${ }^{6}$ Although the current model preserves the initial firm uncertainty over productivity and also the endogenous, forward looking, firm entry decision, it greatly simplifies

\footnotetext{
${ }^{5}$ As was previously mentioned, one of the robust empirical patterns emerging from recent industry studies is that new entrants are much more likely to have lower productivity and exit than do older incumbents. This evidence conflicts with the notion that firm productivity differences are "innate" and known to firms prior to entry. It rather suggests that uncertainty concerning productivity is an important feature that explains the behavior of prospective and new entrants.

${ }^{6}$ Montagna (1995) also adapts Hopenhayn's model to a monopolistic competition environment (in a partial equilibrium setting), but confines the analysis to a static equilibrium with no entry or exit and further constrains the distribution of firm productivity levels to be uniform. Unfortunately, the relevance of her work is difficult to assess because a questionable formulation of equilibrium is used. In the derived equilibrium, all firms produce for one period - regardless of their productivity. Although it is assumed that only the more productive firms earning positive profits remain in the industry in future periods, the present value of these profits flows does not enter into the firms' entry decision. This renders the magnitude of the entry cost inconsequential to the derived equilibrium. This equilibrium therefore does not respond to changes in the entry cost while being overly sensitive to the magnitude of the losses incurred by firms who exit the industry.
} 
the ensuing firm productivity dynamics. Hopenhayn shows how these dynamics shape the equilibrium distribution of firm productivity and analyzes the impact of these dynamics on firm value and the performance of cohorts of firms over time. My model foregoes this type of analysis and instead relies on the choice of a suitable distribution of initial firm productivity levels in order to generate a realistic shape for the equilibrium distribution of firm productivity. The benefit of this simplification is a gain in the tractability of the model that permits a detailed analysis of the impact of trade on both aggregate industry performance and the relative performance of different types of firms (indexed by productivity). As in Hopenhayn (1992b), I restrict the equilibrium analysis to equilibria that maintain a stable aggregate industry environment over time. Forward looking firms correctly anticipate this aggregate environment when making all decisions (including entry). As the impact of any firm on the industry is assumed to be negligible, the equilibrium preserves a stable aggregate environment even though the fortunes of individual firms change, generating simultaneous entry and exit.

\section{Setup of the Model}

\section{Demand}

The preferences of a representative consumer are given by a C.E.S. utility function over a continuum of goods indexed by $\omega$ :

$$
U=\left[\int_{\omega \in \Omega} q(\omega)^{\rho} d \omega\right]^{1 / \rho} .
$$

The measure of the set $\Omega$ will represent the mass (or alternatively, the number) of available goods. These goods will be substitutes, implying $0<\rho<1$ and an elasticity of substitution between any two goods of $\sigma=\frac{1}{1-\rho}>1$. As was originally shown by Dixit and Stiglitz (1977), consumer behavior can be modeled by considering the set of varieties consumed as an aggregate good $Q \equiv U$ associated with an aggregate price

$$
P=\left[\int_{\omega \in \Omega} p(\omega)^{1-\sigma} d \omega\right]^{\frac{1}{1-\sigma}} .
$$

These aggregates can then be used to derive the optimal consumption decisions over individual varieties using

$$
q(\omega)=Q\left(\frac{p(\omega)}{P}\right)^{-\sigma}
$$


which, in turn, yields an expenditure over varieties of

$$
r(\omega)=R\left(\frac{p(\omega)}{P}\right)^{1-\sigma}
$$

where $R=P Q=\int_{\omega \in \Omega} r(\omega) d \omega$ denotes aggregate expenditure.

\section{Production}

There is a continuum of firms, each choosing to produce a different variety $\omega$. Production requires only one factor, labor, which is inelastically supplied at its aggregate level $L$ (which also indexes the size of the economy). Firm technology is represented by a cost function that exhibits constant marginal cost with a fixed overhead cost. Labor used is thus a linear function of output $q$ :

$$
l=f+\frac{q}{\varphi} .
$$

All firms share the same fixed cost $f>0$ but have different productivity levels indexed by $\varphi>0$. Regardless of its productivity, each firm faces a residual demand curve with constant elasticity $\sigma$ and thus chooses the same profit maximizing markup equal to $\frac{\sigma}{\sigma-1}=\frac{1}{\rho}$. This yields a pricing rule

$$
p(\varphi)=\frac{w}{\rho \varphi}
$$

where $w$ is the common wage rate hereafter normalized to one. Firm profit is then

$$
\pi(\varphi)=r(\varphi)-l(\varphi)=\frac{r(\varphi)}{\sigma}-f
$$

where $r(\varphi)$ is firm revenue and $\frac{r(\varphi)}{\sigma}$ is variable profit. $r(\varphi)$ (and hence $\pi(\varphi)$ ) also depend on the aggregate price and revenue as shown in (2):

$$
\begin{aligned}
r(\varphi) & =R(P \rho \varphi)^{\sigma-1} \\
\pi(\varphi) & =\frac{R}{\sigma}(P \rho \varphi)^{\sigma-1}-f .
\end{aligned}
$$


On the other hand, the ratios of any two firms' outputs and revenues only depend on the ratio of their productivity levels:

$$
\frac{q\left(\varphi_{1}\right)}{q\left(\varphi_{2}\right)}=\left(\frac{\varphi_{1}}{\varphi_{2}}\right)^{\sigma} \quad \text { and } \quad \frac{r\left(\varphi_{1}\right)}{r\left(\varphi_{2}\right)}=\left(\frac{\varphi_{1}}{\varphi_{2}}\right)^{\sigma-1}
$$

In summary, a more productive firm (higher $\varphi$ ) will be bigger (larger output and revenues), charge a lower price, and earn higher profits than a less productive firm.

\section{Aggregation}

An equilibrium will be characterized by a mass $M$ of firms (and hence $M$ goods) and a distribution $\mu(\varphi)$ of productivity levels over a subset of $(0, \infty)$. In such an equilibrium, the aggregate price $P$ defined in (1) is then given by

$$
P=\left[\int_{0}^{\infty} p(\varphi)^{1-\sigma} M \mu(\varphi) d \varphi\right]^{\frac{1}{1-\sigma}}
$$

Using the pricing rule (3), this can be written

$$
P=M^{\frac{1}{1-\sigma}} p(\tilde{\varphi}), \quad \text { where } \quad \tilde{\varphi}=\left[\int_{0}^{\infty} \varphi^{\sigma-1} \mu(\varphi) d \varphi\right]^{\frac{1}{\sigma-1}}
$$

$\tilde{\varphi}$ is a weighted average of the firm productivity levels $\varphi$ and is independent of the number of firms $M .^{7}$ These weights reflect the relative output shares of firms with different productivity levels. ${ }^{8} \tilde{\varphi}$ also represents aggregate productivity because it completely summarizes the information in the distribution of productivity levels $\mu(\varphi)$ relevant for all aggregate variables (see appendix):

$$
\begin{array}{ll}
P=M^{\frac{1}{1-\sigma}} p(\tilde{\varphi}), & R=P Q=M r(\tilde{\varphi}), \\
Q=M^{1 / \rho} q(\tilde{\varphi}), & \Pi=M \pi(\tilde{\varphi}),
\end{array}
$$

where $R=\int_{0}^{\infty} r(\varphi) M \mu(\varphi) d \varphi$ and $\Pi=\int_{0}^{\infty} \pi(\varphi) M \mu(\varphi) d \varphi$ represent aggregate revenue (or expenditure) and profit. Thus, an industry comprised of $M$ firms with any distribution of productivity levels $\mu(\varphi)$ that yields the same average productivity level $\tilde{\varphi}$ will also induce the same aggregate

\footnotetext{
${ }^{7}$ Subsequent conditions on the equilibrium $\mu(\varphi)$ must of course ensure that $\tilde{\varphi}$ is finite.

${ }^{8}$ Using $\frac{q(\varphi)}{q(\tilde{\varphi})}=\left(\frac{\varphi}{\tilde{\varphi}}\right)^{\sigma}$ (see $\left.(6)\right), \tilde{\varphi}$ can be written as $\tilde{\varphi}=\left[\int_{0}^{\infty} \varphi^{-1} \frac{q(\varphi)}{q(\tilde{\varphi})} \mu(\varphi) d \varphi\right]^{-1} \cdot \tilde{\varphi}$ is therefore the weighted harmonic mean of the $\varphi$ 's where the weights $\frac{q(\varphi)}{q(\tilde{\varphi})}$ index the firms' relative output shares.
} 
outcome as an industry with $M$ representative firms sharing the same productivity level $\varphi=\tilde{\varphi}$. This variable will be alternatively referred to as aggregate or average productivity. Further note that $\bar{r}=\frac{R}{M}$ and $\bar{\pi}=\frac{\Pi}{M}$ represent both the average revenue and profit per firm as well as the revenue and profit level of the firm with average productivity level $\varphi=\tilde{\varphi}$.

\section{$4 \quad$ Firm Entry and Exit}

There is a large (unbounded) pool of prospective entrants into the industry. Prior to entry, firms are identical. To enter, firms must first make an initial investment, modeled as a fixed entry cost $f_{e}>0$ (measured in units of labor), which is thereafter sunk. Firms then draw their initial productivity parameter $\varphi$ from a common distribution $g(\varphi) .{ }^{9} g(\varphi)$ has positive support over $(0, \infty)$ and has a continuous cumulative distribution $G(\varphi)$. The absence of an upper bound on productivity is assumed only for simplicity; an upper bound can be incorporated in the analysis without qualitatively changing any of the main results.

Upon entry with a low productivity draw, a firm may decide to immediately exit and not produce. If the firm does produce, it then faces a constant (across productivity levels) probability $\delta$ in every period of a bad shock that would force it to exit. Although there are some realistic examples of severe shocks that would constrain a firm to exit independently of productivity (such as natural disasters, new regulation, product liability, major changes in consumer tastes), it is also likely that exit may be caused by a series of bad shocks affecting the firm's productivity. This type of firm level process is explicitly modeled by Hopenhayn $(1992 a, 1992 b)$. He then shows how these firm level productivity dynamics give the equilibrium distribution of productivity levels $\mu(\varphi)$ a different shape than the ex-ante distribution $g(\varphi)$, and determine the ex-ante survival probabilities for a firm, conditional on successful entry. The current model foregoes this type of analysis and assumes that the shape of the equilibrium distribution and the ex-ante survival probabilities are exogenously determined by $g(\varphi)$ and $\delta$. On the other hand, the range of productivity levels, and hence the average productivity level, are endogenously determined. The increased tractability afforded by these simplifications permits the detailed analysis of the impact of trade on this endogenous range of productivity levels and on the distribution of market shares and profits across this range. Since the probability $\delta$ and especially the shape of $g(\varphi)$ are left unrestricted, it is extremely unlikely that

\footnotetext{
${ }^{9}$ This captures the fact that firms can not know their own productivity with certainty until they start producing and selling their good. (Recall that productivity differences may reflect cost differences as well as differences in consumer valuations of the good.)
} 
these simplifications will bias the predictions of the model. Importantly, this simplified industry model will nevertheless generate the main empirical patterns described in the introduction: Since a portion of the firms who exit are those who entered with a low productivity draw (and immediately exit), the overall probability of exit will be negatively correlated with both firm productivity and age. ${ }^{10}$ Furthermore, the model also generates the empirical pattern that the average productivity level of all entrants and exiting firms (including the firms whose entry is unsuccessful) is lower than the average productivity of incumbents. The assumption of the exogenous probability of exit $\delta$ among incumbents does preclude the analysis of the evolution of firm cohorts after the first period following entry. On the other hand, the model preserves the essential features that separates the cohort of new entrants from the incumbents and explains the endogenous selection of heterogeneous firms into the industry.

As previously mentioned, this paper will only consider steady state equilibria, in which the aggregate variables remain constant over time. Since each firm's productivity level does not change over time, its optimal per period profit level (excluding $f_{e}$ ) will also remain constant. An entering firm with productivity $\varphi$ would then immediately exit if this profit level were negative (and hence never produce), or would produce and earn $\pi(\varphi) \geq 0$ in every period until it is hit with the bad shock and is forced to exit. Assuming that there is no time discounting, ${ }^{11}$ each firm's value function will be given by

$$
v(\varphi)=\max \left\{0, \sum_{t=0}^{\infty}(1-\delta)^{t} \pi(\varphi)\right\}=\max \left\{0, \frac{1}{\delta} \pi(\varphi)\right\},
$$

where the dependence of $\pi(\varphi)$ on $R$ and $P$ from (5) is understood. Thus, $\varphi^{*}=\inf \{\varphi: v(\varphi)>0\}$ identifies the lowest productivity level (hereafter referred to as the cutoff level) of producing firms (recall that $\pi(\varphi)$ is strictly increasing in $\varphi$ ). Since $\pi(0)=-f$ is negative, $\pi\left(\varphi^{*}\right)$ must be equal to zero. This will be referred to as the zero cutoff profit condition.

Any entering firm drawing a productivity level $\varphi<\varphi^{*}$ will immediately exit and never produce. Since subsequent firm exit is assumed to be un-correlated with productivity, the exit process will not affect the equilibrium productivity distribution $\mu(\varphi)$. This distribution must then be determined by the initial productivity draw, conditional on successful entry. Hence, $\mu(\varphi)$ will be given by the

\footnotetext{
${ }^{10}$ In this stylized model, firms who enter with low productivity draws exit immediately and do not produce. A period in this model would then correspond, in the real world, to a time span of a couple years during which a new firm makes the decision to stay or exit. The output produced by these new firms who subsequently exit during this period is ignored in this model. Passive learning effects, as in Jovanovic (1982), whereby new firms learn about their unknown productivity levels through noisy cost signals, are probably quite important during this early stage.

${ }^{11}$ Again, this is assumed for simplicity. The probability of exit $\delta$ introduces an effect similar to time discounting. Modeling an additional time discount factor would not qualitatively change any of the results.
} 
conditional of $g(\varphi)$ on $\left[\varphi^{*}, \infty\right)$, that is

$$
\mu(\varphi)= \begin{cases}\frac{g(\varphi)}{1-G\left(\varphi^{*}\right)} & \text { if } \varphi \geq \varphi^{*} \\ 0 & \text { otherwise }\end{cases}
$$

where $p_{i n}=1-G\left(\varphi^{*}\right)$ is the ex-ante probability of successful entry. ${ }^{12}$ This defines the aggregate productivity level $\tilde{\varphi}$ as a function of the cutoff level $\varphi^{*}:{ }^{13}$

$$
\tilde{\varphi}\left(\varphi^{*}\right)=\left[\frac{1}{1-G\left(\varphi^{*}\right)} \int_{\varphi^{*}}^{\infty} \varphi^{\sigma-1} g(\varphi) d \varphi\right]^{\frac{1}{\sigma-1}}
$$

The assumption of a finite $\tilde{\varphi}$ imposes certain restrictions on the size of the upper tail of the distribution $g(\varphi)$ : the $(\sigma-1)^{\text {th }}$ un-centered moment of $g(\varphi)$ must be finite. (8) clearly shows how the shape of the equilibrium distribution of productivity levels is tied to the exogenous exante distribution $g(\varphi)$ while allowing the range of productivity levels (indexed by the cutoff $\varphi^{*}$ ) to be endogenously determined. ${ }^{14}$ (9) then shows how this endogenous range affects the aggregate productivity level.

\section{Zero Cutoff Profit Condition}

Since the average productivity level $\tilde{\varphi}$ is completely determined by the cutoff productivity level $\varphi^{*}$, the average profit and revenue levels are also tied to the cutoff level $\varphi^{*}$ (see $\left.(6)\right)$ :

$$
\bar{r}=r(\tilde{\varphi})=\left(\frac{\tilde{\varphi}\left(\varphi^{*}\right)}{\varphi^{*}}\right)^{\sigma-1} r\left(\varphi^{*}\right) \quad \text { and } \quad \bar{\pi}=\pi(\tilde{\varphi})=\left(\frac{\tilde{\varphi}\left(\varphi^{*}\right)}{\varphi^{*}}\right)^{\sigma-1} \frac{r\left(\varphi^{*}\right)}{\sigma}-f
$$

\footnotetext{
${ }^{12}$ The equilibrium distribution $\mu(\varphi)$ can be determined from the distribution of initial productivity with certainty by applying a law of large numbers to $g(\varphi)$ : recall that individual firms have zero mass, so a positive mass of entering firms requires an infinite number of draws from the distribution $g(\varphi)$. Although some technical problems may arise when applying a law of large numbers to a continuum of random variables, this will not be the case in the current situation. See Hopenhayn (1992a, Note 5) and the reference to Feldman and Gilles (1985) for further details.

${ }^{13}$ This dependence of $\tilde{\varphi}$ on $\varphi^{*}$ is understood when it is subsequently written without its argument.

${ }^{14}$ (8) also illustrates the earlier discussion concerning firm cohorts. All cohorts of incumbent firms will have the same distribution of productivity levels $\mu(\varphi)$. The model thus does not differentiate between cohorts of incumbent firms. These incumbents essentially form one cohort. This cohort is then critically differentiated from that formed by new entrants, whose distribution of productivity levels is given by $g(\varphi)$.
} 
The zero cutoff profit condition, by pinning down the revenue of the cutoff firm, then implies a relationship between the average profit per firm and the cutoff productivity level:

$$
\begin{aligned}
\pi\left(\varphi^{*}\right)=0 & \Longleftrightarrow r\left(\varphi^{*}\right)=\sigma f \\
& \Longleftrightarrow \bar{\pi}=\left(\frac{\tilde{\varphi}\left(\varphi^{*}\right)}{\varphi^{*}}\right)^{\sigma-1} f-f \\
& \Longleftrightarrow \bar{\pi}=f k\left(\varphi^{*}\right),
\end{aligned}
$$

where $k\left(\varphi^{*}\right)=\left(\frac{\tilde{\varphi}\left(\varphi^{*}\right)}{\varphi^{*}}\right)^{\sigma-1}-1=\frac{\bar{r}}{r\left(\varphi^{*}\right)}-1$ is the percentage difference between the average and cutoff firm revenues, as a function of the cutoff productivity level $\varphi^{*}$.

\section{Free Entry and the Value of Firms}

Since all incumbent firms - other than the cutoff firm - earn positive profits, the average profit level $\bar{\pi}$ must be positive. In fact, the expectation of future positive profits is the only reason that firms consider sinking the investment cost $f_{e}$ required for entry. Let $\bar{v}$ represent the present value of the average profit flows:

$$
\bar{v}=\sum_{t=0}^{\infty}(1-\delta)^{t} \bar{\pi}=\frac{1}{\delta} \bar{\pi}
$$

$\bar{v}$ is also the average value of firms, conditional on successful entry: $\bar{v}=\int_{\varphi^{*}}^{\infty} v(\varphi) \mu(\varphi) d \varphi$. Further define $v_{e}$ to be the net value of entry:

$$
v_{e}=p_{i n} \bar{v}-f_{e}=\frac{1-G\left(\varphi^{*}\right)}{\delta} \bar{\pi}-f_{e}
$$

If this value were negative, no firm would want to enter. In any equilibrium where entry is unrestricted, this value could further not be positive since the mass of prospective entrants is unbounded.

\section{Equilibrium in a Closed Economy}

A stationary equilibrium is defined by constant aggregate variables over time and the free entry of firms into the industry. Such an equilibrium is completely referenced by a triplet $\left(\varphi^{*}, P, R\right)$ satisfying the following conditions (see (10) and (11)):

$$
\left\{\begin{array} { l l } 
{ \pi ( \varphi ^ { * } ) = 0 } & { \text { (Zero Cutoff Profit) } } \\
{ v _ { e } = 0 } & { \text { (Free Entry) } }
\end{array} \Longleftrightarrow \left\{\begin{array}{ll}
\bar{\pi}=f k\left(\varphi^{*}\right) & (\mathrm{ZCP}) \\
\bar{\pi}=\frac{\delta f_{e}}{1-G\left(\varphi^{*}\right)} & (\mathrm{FE})
\end{array}\right.\right.
$$


Since the aggregate price index $(P)$, revenue $(R)$, and productivity level $(\tilde{\varphi})$ remain constant, all other aggregate variables must also remain constant. ${ }^{15}$ The equilibrium mass of firms $M$ is determined from the aggregate price index and aggregate productivity level using the aggregation condition $P=M^{\frac{1}{1-\sigma}} p(\tilde{\varphi})=M^{\frac{1}{1-\sigma}} \frac{1}{\rho \tilde{\varphi}}$. This stationary equilibrium also requires a mass $M_{e}$ of new entrants in every period, such that the mass of successful entrants, $p_{i n} M_{e}$, exactly replaces the mass $\delta M$ of incumbents who are hit with the bad shock and exit: $p_{i n} M_{e}=\delta M$ (This will be subsequently referred to as the aggregate stability condition.) The equilibrium distribution of productivity $\mu(\varphi)$ is not affected by this simultaneous entry and exit since the successful entrants and failing incumbents have the same distribution of productivity levels.

The labor used by these new entrants for investment purposes must, of course, be reflected in the accounting for aggregate labor $L$, and affects the aggregate labor available for production: $L=L_{p}+L_{e}$ where $L_{p}$ and $L_{e}$ represent the aggregate labor used for production and investment (by new entrants). Aggregate payments to production workers $L_{p}$ must match the difference between aggregate revenue and profit: $L_{p}=R-\Pi$ (this is also the labor market clearing condition for production workers). The market clearing condition for investment workers requires $L_{e}=M_{e} f_{e}$. Using the aggregate stability condition $\left(p_{i n} M_{e}=\delta M\right)$ and the free entry condition $\left(\bar{\pi}=\frac{\delta f_{e}}{1-G\left(\varphi^{*}\right)}\right)$, $L_{e}$ can be written:

$$
L_{e}=M_{e} f_{e}=\frac{\delta M}{p_{\text {in }}} f_{e}=M \bar{\pi}=\Pi .
$$

Thus, aggregate revenue $R=L_{p}+\Pi=L_{p}+L_{e}$ must also equal the total payments to labor $L$ and is therefore exogenously fixed by this index of country size. ${ }^{16}$ The aggregate price index $P$ can then be calculated using

$$
P=M^{\frac{1}{1-\sigma}} p(\tilde{\varphi})=\left(\frac{R}{\bar{r}}\right)^{\frac{1}{1-\sigma}} p(\tilde{\varphi})=\left(\frac{R}{\sigma(\bar{\pi}+f)}\right)^{\frac{1}{1-\sigma}} \frac{1}{\rho \tilde{\varphi}\left(\varphi^{*}\right)}
$$

This condition, along with $(12)$ and $R=L$, completely determines the equilibrium triplet $\left(P, R, \varphi^{*}\right)$.

\footnotetext{
${ }^{15}$ Recall that aggregate productivity $\tilde{\varphi}$ will be a function of the cutoff level $\varphi^{*}$ as shown in (9).

${ }^{16} \mathrm{It}$ is important to emphasize that this result is not a direct consequence of aggregation and market clearing conditions: it is a property of the model's stationary equilibrium. Aggregate income need not necessarily equal the payments to all workers, since there may be some investment income derived from the financing of new entrants. Each new entrant raises the capital $f_{e}$, which provides a random return of $\pi(\varphi)\left(\varphi \geq \varphi^{*}\right)$ or zero $\left(\varphi<\varphi^{*}\right)$ in every period. In equilibrium, the aggregate return $\Pi$ equals the aggregate investment cost $L_{e}$ in every period - so there is no net investment income (this would not be the case with a positive time discount factor).
} 


\section{Existence and Uniqueness of the Equilibrium}

The free entry (FE) and zero cutoff profit (ZCP) conditions represent two different relationships between the average profit level $\bar{\pi}$ and the cutoff productivity level $\varphi^{*}$ (see (12)). These two conditions are discussed in further detail below. I first summarize their important properties for the determination of the equilibrium values of $\varphi^{*}$ and $\bar{\pi}$ : In $(\varphi, \pi)$ space the FE curve is increasing and is cut by the ZCP curve only once from above (see appendix for proof). This ensures the existence and uniqueness of the equilibrium $\varphi^{*}$ and $\bar{\pi}$. Furthermore, upward (downward) shifts of the ZCP curve or downward (upward) shifts of the FE curve must lead to an increase (decrease) in the equilibrium $\varphi^{*}$. The determination of the equilibrium $\varphi^{*}$ and $\bar{\pi}$ is graphically shown in Figure $1 .^{17}$

Inspection of the FE condition $\left(\bar{\pi}=\frac{\delta f_{e}}{1-G\left(\varphi^{*}\right)}\right)$ reveals that it represents an increasing relationship between these two variables. Along the FE curve, $\bar{\pi}$ increases from $\delta f_{e}$ to infinity for $\varphi^{*} \in(0, \infty):$ As $\varphi^{*}$ increases, the probability of successful entry $\left(p_{i n}=1-G\left(\varphi^{*}\right)\right)$ decreases - average profits must therefore increase for firms to remain indifferent about entry. The relationship between $\bar{\pi}$ and $\varphi^{*}$ implied by the zero cutoff profit condition $\left(\bar{\pi}=f k\left(\varphi^{*}\right)\right)$ will depend on $k(\varphi)$, which is in turn determined by the distribution $g(\varphi)$ and the elasticity $\sigma$. Recall that $k\left(\varphi^{*}\right)=\left(\frac{\tilde{\varphi}\left(\varphi^{*}\right)}{\varphi^{*}}\right)^{\sigma-1}-1=\frac{\bar{r}}{r\left(\varphi^{*}\right)}-1$ represents the percentage difference between the average and cutoff firm revenues. As the cutoff level $\varphi^{*}$ goes to zero, the revenue of the cutoff firm also goes to zero. Since the average revenue level is always positive (even when $\varphi^{*} \rightarrow 0$ ), the ratio of the average to cutoff firm revenue becomes infinite as $\varphi^{*}$ goes to zero: Along the ZCP curve, $\bar{\pi} \rightarrow \infty$ as $\varphi^{*} \rightarrow 0$. Further properties of $k(\varphi)$ require some extra regularity assumptions on the distribution $g(\varphi)$. If $g(\varphi)$ belongs to most of the common families of distributions (including the lognormal, exponential, Gamma, or Weibull distributions or truncations on $(0, \infty)$ of the normal, logistic, extreme value, or Laplace distributions), then $k(\varphi)$ will monotonically decrease to zero on $(0, \infty) .{ }^{18}$ In these cases, $\bar{\pi}$ decreases from infinity to zero for $\varphi^{*} \in(0, \infty)$ along the ZCP curve, as shown in Figure 1.

\footnotetext{
${ }^{17}$ Although the ZCP curve must cut the FE curve from above, it is not necessarily downward sloping as represented in the graph. The following discussion provides some mild additional assumptions on the shape of $g(\varphi)$ that ensure that the ZCP curve monotonically decreases to zero as shown in the graph.

${ }^{18}$ Sufficient conditions for this property are that $\frac{g(\varphi) \varphi}{1-G(\varphi)}$ be increasing and unbounded from above on $(0, \infty)$. These regularity conditions ensure that an increase in the cutoff level $\varphi^{*}$ redistributes the mass of incumbent firms towards the cutoff level. This pushes the average productivity level $\tilde{\varphi}$ closer to the cutoff $\varphi^{*}$, and hence reduces the percentage difference between the revenues of the average and cutoff firms.
} 


\section{Analysis of the Equilibrium}

As was just shown, the equilibrium productivity cutoff level, $\varphi^{*}$, and average firm profit, $\bar{\pi}$, do not depend on the country size $L$. Hence, the equilibrium distribution of productivity levels $\mu(\varphi)$ and average productivity level $\tilde{\varphi}$ will also be independent of country size. Average firm revenue $\bar{r}=\sigma(\bar{\pi}+f)$ will also be independent of $L$ and can be used to determine the number of firms:

$$
M=\frac{R}{\bar{r}}=\frac{L}{\sigma(\bar{\pi}+f)} .
$$

Hence, a large and small country will share the same firm level variables (same $\varphi^{*}, \tilde{\varphi}, \bar{r}, \bar{\pi}$ ). The large country will just have more firms in an amount proportional to its country size. This larger number of firms will nevertheless be identically distributed over the same productivity range $\left[\varphi^{*}, \infty\right)$ as will be the firms from the small country. Welfare per worker, which is given by

$$
W=P^{-1}=M^{\frac{1}{\sigma-1}} \rho \tilde{\varphi}
$$

will be higher in the large country due only to increased product variety. This influence of country size on the determination of aggregate variables is identical to that derived by Krugman (1980) with representative firms. Once $\tilde{\varphi}$ and $\bar{\pi}$ are determined, the aggregate outcome predicted by this model is identical to one generated by an economy with representative firms who share the same productivity level $\tilde{\varphi}$ and profit level $\bar{\pi}$. On the other hand, this model with heterogeneous firms explains how the aggregate productivity level $\tilde{\varphi}$ and the average firm profit level $\bar{\pi}$ are endogenously determined and how both can change in response to various shocks. In particular, a country's production technology (referenced by the distribution $g(\varphi)$ ) need not change in order to induce changes in aggregate productivity. In the following sections, I argue that the exposure of a country to trade creates precisely the type of shock that induces reallocations between firms and generates increases in aggregate productivity. These results can not be explained by representative firm models where the aggregate productivity level is exogenously given as the productivity level common to all firms. Changes in aggregate productivity can then only result from changes in firm level technology and not from reallocations. 


\section{Comparative Statics}

Before using this model to analyze the industry and firm level responses to changes in trade regime, two of the comparative statics of the closed economy model are briefly described. An increase in the sunk entry cost $f_{e}$ will shift up the FE curve and lower the equilibrium cutoff level $\varphi^{*}$. Aggregate productivity must then decrease with the cutoff level $(\tilde{\varphi}$ is an increasing function of $\left.\varphi^{*}\right)$. Although the direction of the change in product variety is ambiguous (product variety will decrease so long as the ZCP curve is downward sloping), the decrease in aggregate productivity is enough to unambiguously entail a welfare loss (see appendix for proof). If an upper bound on firm productivity were incorporated into this model, then the possibility of representative firms is obtained as a limiting case when the entry cost goes to zero. In this case, the cutoff level $\varphi^{*}$ and average level $\tilde{\varphi}$ are both pushed towards the productivity upper bound and the average profit level is driven to zero, as shown in Figure 2.

An increase in the fixed production cost $f$ will shift up the ZCP curve and therefore raise the equilibrium cutoff level $\varphi^{*}$, along with aggregate productivity: firms previously producing with low productivity levels can no longer earn positive profits and exit. The average profit level $\bar{\pi}$ must increase, as the FE curve is upward sloping. The higher profit level will, in turn, imply a decrease in product variety (see (14)). The product variety decrease and the aggregate productivity increase have opposite effects on welfare. In the appendix, it is shown that the sign of the welfare change is negative and hence that the lower product variety effect dominates that of the higher aggregate productivity. This yields the reasonable property that higher production costs have an overall negative impact on welfare.

\section{Overview and Assumptions of the Open Economy Model}

I now examine the impact of trade in a world (or trade bloc) that is composed of countries whose economies are of the type that was previously described. When there are no additional costs associated with trade, then trade allows the individual countries to replicate the outcome of the integrated world economy. ${ }^{19}$ Trade then provides the same opportunities to an open economy as would an increase in country size to a closed economy. As was previously discussed, an increase in country size has no effect on firm level outcomes. The transition to trade will thus not affect

\footnotetext{
${ }^{19}$ Consumers in every country have access to the same bundle of goods at the same aggregate price index. Firms behave as if they were selling their product in the integrated world market. The FE and ZCP conditions will be identical across countries and will not be affected by the transition to trade.
} 
any of the firm level variables $\left(\varphi^{*}, \tilde{\varphi}, \bar{r}, \bar{\pi}\right)$ : The same number of firms in each country produce at the same output levels and earn the same profits as they did in the closed economy. All firms in a given country divide their sales between domestic and foreign consumers, based on the size of their country relative to the integrated world economy. Thus, in the absence of any costs to trade, the existence of firm heterogeneity does not affect the impact of trade. This impact is identical to the one described by Krugman (1980) with representative firms: Although firms are not affected by the transition to trade, consumers enjoy welfare gains driven by the increase in product variety. ${ }^{20}$

On the other hand, there is mounting evidence that firms wishing to export not only face perunit costs (such as transport costs and tariffs), but also - critically - face some fixed costs that do not vary with export volume. In a world with firm level heterogeneity, the existence of such costs provides the most consistent explanation for the widely observed pattern that, across countries and industries, certain firms do not export while others in the same narrowly defined industry do. Interviews with managers making export decisions confirm that firms in differentiated product industries face significant fixed costs associated with the entry into export markets (see Roberts and Tybout (1997b)): A firm must find and inform foreign buyers about its product and learn about the foreign market. It must then research the foreign regulatory environment and adapt its product to ensure that it conforms to foreign standards (which include testing, packaging, and labeling requirements). An exporting firm must also set up new distribution channels in the foreign country and conform to all the shipping rules specified by the foreign customs agency. Although some of these costs can not be avoided, others are often manipulated by governments in order to erect non-tariff barriers (NTBs) to trade. Regardless of their origin, these costs are most appropriately modeled as independent of the firm's export volume decision. ${ }^{21}$

When there is uncertainty concerning the export market, the timing and sunk nature of the

\footnotetext{
${ }^{20}$ The irrelevance of firm heterogeneity for the impact of trade is not just a consequence of negligible trade costs. The assumption of an exogenously fixed elasticity of substitution between varieties also plays a significant role in this result. The presence of heterogeneity (even in the absence of trade costs) plays a significant role in determining the impact of trade once this assumption is dropped. In a separate appendix (available upon request to the author), the current model is modified by allowing the elasticity of substitution to endogenously increase with product variety. This link between trade and the elasticity of substitution was studied by Krugman (1979) with representative firms. In the context of the current model, the appendix shows how the size of the economy then affects the aggregate productivity level and the skewness of market shares and profits across firms with different productivity levels. Larger economies have higher aggregate productivity levels - even though they have the same firm level technology index by $g(\varphi)$. Therefore, even in the absence of trade costs, trade increases the size of the "world" economy and induces reallocations of market shares and profits towards more productive firms and generates an aggregate productivity gain.

${ }^{21}$ The modeling of a fixed export cost is not new. Bernard and Jensen (1999a), Clerides, Lach and Tybout (1998), Roberts and Tybout (1997a), and Roberts, Sullivan and Tybout (1995) all introduce a fixed export cost into the theoretical sections of their work in order to explain the self-selection of firms into the export market. However, these analyses are restricted to a partial equilibrium setting in which the distribution of firm productivity levels is fixed.
} 
costs become quite relevant for the export decision (most of the previously mentioned costs must be sunk prior to entry into the export market). ${ }^{22}$ The strong and robust empirical correlations at the firm level between export status and productivity suggest that the export market entry decision occurs after the firm gains knowledge of its productivity, and hence that uncertainty concerning the export markets is not predominantly about productivity (as is the uncertainty prior to entry into the industry). I therefore assume that a firm who wishes to export must make an initial fixed investment, but that this investment decision occurs after the firm's productivity is revealed. For simplicity, I do not model any additional uncertainty concerning the export markets. The per-unit trade costs are modeled in the standard iceberg formulation, whereby $\tau>1$ units of a good must be shipped in order for 1 unit to arrive at destination.

Although the size of a country relative to the rest of the world (which constitutes its trading partners) is left unrestricted, I do assume that the world (or trading group) is comprised of some number of identical countries. In other words, a representative country framework is assumed. This assumption is made in order to ensure factor price equalization across countries and hence focus the analysis on firm selection effects that are independent of wage differences. In this model with fixed export costs, countries who differ only in country size can exhibit different wage rates in the equilibrium with trade. These wage differences then induce further firm selection effects and aggregate productivity differences across countries. ${ }^{23}$ I thus assume that the economy under study can trade with $n \geq 1$ other countries (the world is then comprised of $n+1 \geq 2$ countries). Firms can export their products to any country, although entry into each of these export markets requires a fixed investment cost of $f_{e x}>0$ (measured in units of labor). Regardless of export status, a firm still incurs the same overhead production cost $f$.

\section{Equilibrium in the Open Economy}

The symmetry assumption ensures that all countries share the same wage, which is still normalized to one, and also share the same aggregate variables. Each firm's pricing rule in its domestic market is given, as before, by $p_{d}(\varphi)=\frac{w}{\rho \varphi}=\frac{1}{\rho \varphi}$. Firms who export will set higher prices in the foreign markets that reflect the increased marginal cost $\tau$ of serving these markets: $p_{x}(\varphi)=\frac{\tau}{\rho \varphi}=\tau p_{d}(\varphi)$. Thus, the revenues earned from domestic sales and export sales to any given country are, respectively:

\footnotetext{
${ }^{22}$ Roberts and Tybout (1997a) find that the sunk nature of these costs and the foreign market uncertainty play a significant role in explaining hysteresis effects associated with firm level export decisions in Colombia.

${ }^{23}$ In these asymmetric equilibria with fixed export costs, large countries enjoys higher aggregate productivity, welfare, and wages relative to smaller countries. The analysis of these equilibria is left for future work.
} 


$$
r_{d}(\varphi)=R(P \rho \varphi)^{\sigma-1} \quad \text { and } \quad r_{x}(\varphi)=\tau^{1-\sigma} r_{d}(\varphi)
$$

where $R$ and $P$ denote the aggregate expenditure and price index in every country. The balance of payments condition implies that $R$ also represents the aggregate revenue of firms in any country, and hence aggregate income. The combined revenue of a firm, $r(\varphi)$, thus depends on its export status:

$$
r(\varphi)= \begin{cases}r_{d}(\varphi) & \text { if the firm does not export } \\ r_{d}(\varphi)+n r_{x}(\varphi)=\left(1+n \tau^{1-\sigma}\right) r_{d}(\varphi) & \text { if the firm exports to all countries }\end{cases}
$$

If some firms do not export, then there no longer exists an integrated world market for all goods. Even though the symmetry assumption ensures that all the characteristics of the goods available in every country are similar, the actual bundle of goods available will be different across countries: consumers in each country have access to goods (produced by the non-exporting firms) that are not available to consumers in any other country.

\section{Firm Entry, Exit, and Export Status}

All the exogenous factors affecting firm entry, exit, and productivity levels remain unchanged by trade. Prior to entry, firms face the same ex-ante distribution of productivity levels $g(\varphi)$. Firms whose entry is successful produce with the same productivity level $\varphi$ in every period. They all face the same probability $\delta$ of a bad shock that would force them to exit. Upon entry with a low productivity draw, a firm may decide to immediately exit and not produce. In a stationary equilibrium, any incumbent firm with productivity $\varphi$ earns variable profits $\frac{r_{x}(\varphi)}{\sigma}$ in every period from its export sales to any given country. Since the export cost is assumed equal across countries, a firm will either export to all countries in every period or never export. ${ }^{24}$ Given that the export decision occurs after firms know their productivity $\varphi$, and since there is no additional export market uncertainty, firms are indifferent between paying the one time investment cost $f_{e x}$, or paying the amortized per-period portion of this cost $f_{x}=\delta f_{e x}$ in every period (as before, there is no additional time discounting other than the probability of the exit inducing shock $\delta$ ). This per-period representation of the export cost is henceforth adopted for notational simplicity. In the

\footnotetext{
${ }^{24}$ The restriction that export costs are equal across countries can be relaxed. Some firms then export to some countries but not others - depending on these cost differences. This extension would also generate an increasing relationship between a firm's productivity and the number of countries it exports to.
} 
stationary equilibrium, the aggregate labor resources used in every period to cover the export costs do not depend on this choice of representation. ${ }^{25}$ The per-period profit flow of any exporting firm then reflects the per-period fixed cost $f_{x}$, which is incurred per export country.

Since no firm will ever export and not also produce for its domestic market ${ }^{26}$ each firm's profit can be separated into portions earned from domestic sales $\left(\pi_{d}(\varphi)\right)$ and export sales per country $\left(\pi_{x}(\varphi)\right)$ by accounting for the entire overhead production cost in domestic profit:

$$
\pi_{d}(\varphi)=\frac{r_{d}(\varphi)}{\sigma}-f \quad \text { and } \quad \pi_{x}(\varphi)=\frac{r_{x}(\varphi)}{\sigma}-f_{x}
$$

A firm who produces for its domestic market exports to all $n$ countries if $\pi_{x}(\varphi) \geq 0$. Each firm's combined profit can then be written:

$$
\pi(\varphi)=\pi_{d}(\varphi)+\max \left\{0, n \pi_{x}(\varphi)\right\}
$$

As before, a firm's value is the present value (discounted by the probability of the bad shock) of its profit flows, $v(\varphi)=\max \left\{0, \frac{1}{\delta} \pi(\varphi)\right\}$, and $\varphi^{*}=\inf \{\varphi: v(\varphi)>0\}$ still identifies the cutoff productivity level for successful entry into the industry. Additionally, $\varphi_{x}^{*}=\inf \left\{\varphi: \varphi \geq \varphi^{*}\right.$ and $\left.\pi_{x}(\varphi)>0\right\}$ now represents the cutoff productivity level for exporting firms. If $\varphi_{x}^{*}=\varphi^{*}$, then all firms in the industry export. In this case, the cutoff firm (with productivity level $\varphi^{*}=\varphi_{x}^{*}$ ) earns zero total profit $\left(\pi\left(\varphi^{*}\right)=\pi_{d}\left(\varphi^{*}\right)+n \pi_{x}\left(\varphi^{*}\right)=0\right)$ and non-negative export profit $\left(\pi_{x}\left(\varphi^{*}\right) \geq 0\right)$. If $\varphi_{x}^{*}>\varphi^{*}$, then some firms (with productivity levels between $\varphi^{*}$ and $\varphi_{x}^{*}$ ) produce exclusively for their domestic market. These firms do not export as their export profits would be negative $\left(\pi_{x}(\varphi)<0\right)$. They earn non-negative profits exclusively from their domestic sales $\left(\pi(\varphi)=\pi_{d}(\varphi) \geq 0\right)$. The firms with productivity levels above the second cutoff $\varphi_{x}^{*}$ earn positive profits from both their domestic and export sales. By their definition, the cutoff levels must then satisfy $\pi_{d}\left(\varphi^{*}\right)=0$ and $\pi_{x}\left(\varphi_{x}^{*}\right)=0$. This partitioning of firms by export status will occur if and only if $\tau^{\sigma-1} f_{x}>f$ : the trade costs relative to the overhead production cost must be above a threshold level. Note that, when there are no fixed (sunk) export costs $\left(f_{x}=0\right)$, no level of variable cost $\tau>1$ can induce this partitioning. However, a large enough fixed export cost $f_{x}>f$ will induce partitioning even when there are no

\footnotetext{
${ }^{25}$ In one case, only the new entrants who export expend resources to cover the full investment cost $f_{\text {ex }}$. In the other case, all exporting firms expend resources to cover the smaller amortized portion of the cost $f_{x}=\delta f_{\text {ex }}$. In equilibrium, the ratio of new exporters to all exporters is $\delta$ (see appendix), so the same aggregate labor resources are expended in either case.

${ }^{26}$ A firm would earn strictly higher profits by also producing for its domestic market since the associated variable profit $\frac{r_{d}(\varphi)}{\sigma}$ is always positive and the overhead production cost $f$ is already incurred.
} 
variable trade costs. As the partitioning of firms by export status (within sectors) is empirically ubiquitous, I will henceforth assume that the combination of fixed and variable trade costs are high enough to generate partitioning, and therefore that $\tau^{\sigma-1} f_{x}>f$. Although the equilibrium where all firms export will not be formally derived, it exhibits several similar properties to the equilibrium with partitioning that will be highlighted. ${ }^{27}$

Once again, the equilibrium distribution of productivity levels for incumbent firms, $\mu(\varphi)$, is determined by the ex-ante distribution of productivity levels, conditional on successful entry: $\mu(\varphi)=\frac{g(\varphi)}{1-G\left(\varphi^{*}\right)}, \forall \varphi \geq \varphi^{*} . p_{i n}=1-G\left(\varphi^{*}\right)$ still identifies the ex-ante probability of successful entry. Furthermore, $p_{x}=\frac{1-G\left(\varphi_{x}^{*}\right)}{1-G\left(\varphi^{*}\right)}$ now represents the ex-ante probability that one of these successful firms will export. $p_{x}$ must then also represent the ex-post fraction of firms that export. Let $M$ denote the equilibrium mass of incumbent firms in any country. $M_{x}=p_{x} M$ then represents the mass of exporting firms while $M_{t}=M+n M_{x}$ represents the total mass of varieties available to consumers in any country (or alternatively, the total mass of firms competing in any country).

\section{Aggregation}

Using the same weighted average function defined in $(9)$, let $\tilde{\varphi}=\tilde{\varphi}\left(\varphi^{*}\right)$ and $\tilde{\varphi}_{x}=\tilde{\varphi}\left(\varphi_{x}^{*}\right)$ denote the average productivity levels of, respectively, all firms and exporting firms only. The average productivity across all firms, $\tilde{\varphi}$, is based only on domestic market share differences between firms (as reflected by differences in the firms' productivity levels). If some firms do not export, then this average will not reflect the additional export shares of the more productive firms. Furthermore, neither $\tilde{\varphi}$ nor $\tilde{\varphi}_{x}$ reflect the proportion $\tau$ of output units that are "lost" in export transit. Let $\tilde{\varphi}_{t}$ be the weighted productivity average that reflects the combined market share of all firms and the output shrinkage linked to exporting. Again, using the weighted average function (9), this combined average productivity can be written:

$$
\tilde{\varphi}_{t}=\left(\frac{1}{M_{t}}\left[M \tilde{\varphi}^{\sigma-1}+n M_{x}\left(\tau^{-1} \tilde{\varphi}_{x}\right)^{\sigma-1}\right]\right)^{\frac{1}{\sigma-1}}
$$

By symmetry, $\tilde{\varphi}_{t}$ is also the weighted average productivity of all firms (domestic and foreign) competing in a single country (where the productivity of exporters is adjusted by the trade cost

\footnotetext{
${ }^{27}$ Even when there is no partitioning of firms by export status, the opening of the economy to trade will still induce reallocations and distributional changes among the heterogeneous firms - so long as the fixed export costs are positive $\left(f_{x}=0\right)$. In the absence of such costs (given any level of per-unit costs $\tau$ ), opening to trade will not induce any distributional changes among firms, and heterogeneity will not play an important role.
} 
$\tau)$. As was the case in the closed economy, this productivity average plays an important role as it once again completely summarizes the effects of the distribution of productivity levels $\mu(\varphi)$ on the aggregate outcome. Thus, the aggregate price index $P$, expenditure level $R$, and welfare per worker $W$ in any country can then be written as functions only of the productivity average $\tilde{\varphi}_{t}$ and the number of varieties consumed $M_{t}:{ }^{28}$

$$
P=M_{t}^{\frac{1}{1-\sigma}} p\left(\tilde{\varphi}_{t}\right)=M_{t}^{\frac{1}{1-\sigma}} \frac{1}{\rho \tilde{\varphi}_{t}}, \quad R=M_{t} r_{d}\left(\tilde{\varphi}_{t}\right), \quad W=\frac{R}{L} M_{t}^{\frac{1}{\sigma-1}} \rho \tilde{\varphi}_{t}
$$

By construction, the productivity averages $\tilde{\varphi}$ and $\tilde{\varphi}_{x}$ can also be used to express the average profit and revenue levels across different groups of firms: $r_{d}(\tilde{\varphi})$ and $\pi_{d}(\tilde{\varphi})$ represent the average revenue and profit earned by domestic firms from sales in their own country. Similarly, $r_{x}\left(\tilde{\varphi}_{x}\right)$ and $\pi_{x}\left(\tilde{\varphi}_{x}\right)$ represent the average export revenue and profit (to any given country) across all domestic firms who export. The overall average, across all domestic firms, of combined revenue $(\bar{r})$ and profit $(\bar{\pi})$, earned from both domestic and export sales, is thus given by:

$$
\bar{r}=r_{d}(\tilde{\varphi})+p_{x} n r_{x}\left(\tilde{\varphi}_{x}\right) \quad \text { and } \quad \bar{\pi}=\pi_{d}(\tilde{\varphi})+p_{x} n \pi_{x}\left(\tilde{\varphi}_{x}\right)
$$

\section{Equilibrium Conditions}

As in the closed economy equilibrium, the zero cutoff profit condition will imply a relationship between the average profit per firm $\bar{\pi}$, and the cutoff productivity level $\varphi^{*}$ (see the derivation for $(10))$ :

$$
\left\{\begin{array} { l } 
{ \pi _ { d } ( \varphi ^ { * } ) = 0 } \\
{ \pi _ { x } ( \varphi _ { x } ^ { * } ) = 0 }
\end{array} \Longleftrightarrow \left\{\begin{array}{l}
\pi_{d}(\tilde{\varphi})=f k\left(\varphi^{*}\right) \\
\pi_{x}\left(\tilde{\varphi}_{x}\right)=f_{x} k\left(\varphi_{x}^{*}\right)
\end{array}\right.\right.
$$

where $k(\varphi)=\left[\left(\frac{\tilde{\varphi}(\varphi)}{\varphi}\right)^{\sigma-1}-1\right]$ as was previously defined. The zero cutoff profit condition also implies that $\varphi_{x}^{*}$ can be written as a function of $\varphi^{*}:{ }^{29}$

$$
\frac{r_{x}\left(\varphi_{x}^{*}\right)}{r_{d}\left(\varphi^{*}\right)}=\tau^{1-\sigma}\left(\frac{\varphi_{x}^{*}}{\varphi^{*}}\right)^{\sigma-1}=\frac{f_{x}}{f} \Longleftrightarrow \varphi_{x}^{*}=\varphi^{*} \tau\left(\frac{f_{x}}{f}\right)^{\frac{1}{\sigma-1}}
$$

Using (19), $\bar{\pi}$ can therefore be expressed as a function of the cutoff level $\varphi^{*}$ :

\footnotetext{
${ }^{28}$ In other words, the aggregate equilibrium in any country is identical to one with $M_{t}$ representative firms that all share the same productivity level $\tilde{\varphi}_{t}$.

${ }^{29}$ Recall that $r_{x}(\varphi)=\tau^{1-\sigma} r_{d}(\varphi) \quad \forall \varphi \geq \varphi^{*}$.
} 


$$
\begin{aligned}
\bar{\pi} & =\pi_{d}(\tilde{\varphi})+p_{x} n \pi_{x}\left(\tilde{\varphi}_{x}\right) \\
& =f k\left(\varphi^{*}\right)+p_{x} n f_{x} k\left(\varphi_{x}^{*}\right) \quad(\mathrm{ZCP})
\end{aligned}
$$

where $\varphi_{x}^{*}$, and hence $p_{x}$ are implicitly defined as functions of $\varphi^{*}$ using (20).

As before, $\bar{v}=\sum_{t=0}^{\infty}(1-\delta)^{t} \bar{\pi}=\frac{1}{\delta} \bar{\pi}$ represents the present value of the average profit flows and $v_{e}=p_{i n} \bar{v}-f_{e}$ yields the net value of entry. The free entry condition thus remains unchanged:

$v_{e}=0 \Longleftrightarrow \bar{\pi}=\frac{\delta f_{e}}{p_{i n}}(\mathrm{FE})$. Regardless of profit differences across firms (based on export status), the expected value of future profits, in equilibrium, must equal the fixed investment cost.

\section{Determination of the Equilibrium}

As in the closed economy case, a stationary equilibrium is uniquely determined by the triplet $\left(\varphi^{*}, P, R\right)$ satisfying the free entry and zero cutoff profit conditions. It is shown in the appendix that the free entry condition and the new zero cutoff profit condition and (20)) identify a unique $\varphi^{*}$ and $\bar{\pi}$ (the new ZCP curve still cuts the FE curve from above). The equilibrium $\varphi^{*}$, in turn, determines the export productivity cutoff $\varphi_{x}^{*}$ as well as the average productivity levels $\tilde{\varphi}, \tilde{\varphi}_{x}$, $\tilde{\varphi}_{t}$, and the ex-ante successful entry and export probabilities $p_{i n}$ and $p_{x}$. As was the case in the closed economy equilibrium, the free entry condition and the aggregate stability condition ${ }^{30}\left(p_{\text {in }} M_{e}=\delta M\right)$ ensure that the aggregate payment to the investment workers $L_{e}$ equals the aggregate profit level $\Pi$. Thus, once again, aggregate revenue $R$ is exogenously given by the size of the labor force: $R=L$. As shown in (18), the aggregate price index is determined by the aggregate number of goods available in each country $\left(M_{t}\right)$ and the average productivity level across all firms selling these goods $\left(\tilde{\varphi}_{t}\right)$. It therefore remains to be shown that the number of firms $M$ in either country (and hence, the number of varieties available $\left.M_{t}=\left(1+p_{x}\right) M\right)$ is uniquely determined by the equilibrium conditions.

Following a line of argument similar to the one used in the closed economy case, the number of firms is obtained from the equilibrium conditions by using the property that these conditions

\footnotetext{
${ }^{30}$ Recall that this condition ensures that the mass of successful entrants matches the mass of incumbent firms who exit.
} 
identify the average revenue per firm $(\bar{r})$ independently of $M$ (see (19)):

$$
\begin{aligned}
\bar{r} & =r_{d}(\tilde{\varphi})+p_{x} n r_{x}\left(\tilde{\varphi}_{x}\right) \\
& =\sigma(\bar{\pi}+f)+p_{x} n \sigma\left[\pi_{x}\left(\tilde{\varphi}_{x}\right)+f_{x}\right] \\
& =\sigma\left(\bar{\pi}+f+p_{x} n f_{x}\right),
\end{aligned}
$$

which thus determines the number of firms:

$$
M=\frac{R}{\bar{r}}=\frac{L}{\sigma\left(\bar{\pi}+f+p_{x} n f_{x}\right)} .
$$

Almost all of these equilibrium conditions also apply to the case where all firms export. The only difference is that $\varphi_{x}^{*}=\varphi^{*}$ (and hence $p_{x}=1$ ) and (20) no longer holds.

\section{The Impact of Trade}

The result that the modeling of fixed export costs explains the partitioning of firms by export status and productivity level is not exactly earth-shattering. This can be explained quite easily within a simple partial equilibrium model with a fixed distribution of firm productivity levels. On the other hand, such a model would be ill-suited to address several important questions concerning the impact of trade in the presence of export market entry costs and firm heterogeneity: What happens to the range of firm productivity levels? Do all firms benefit from trade or does the impact depend on a firm's productivity? How is aggregate productivity and welfare affected? The current model is much better suited to address these questions, ${ }^{31}$ which are answered in the following sections. The current section examines the effects of a transition from autarky (the closed economy previously described) to the open economy. The following section then studies the impact of incremental trade liberalization, once the economy is open.

Let $\varphi_{a}^{*}$ and $\tilde{\varphi}_{a}$ denote the cutoff and average productivity levels in autarky. I use the notation of the previous section for all variables and functions pertaining to the new open economy equilibrium. As was previously mentioned, the FE condition is identical in both the closed and open economy. Inspection of the new ZCP condition in the open economy (21) relative to the one in the closed economy (12) immediately reveals that the ZCP curve shifts up: the exposure to trade induces an

\footnotetext{
${ }^{31}$ In order to plausibly address these questions, a model should allow for the endogenous selection of the heterogeneous firms into the industry and incorporate the general equilibrium feedback link between wages and productivity.
} 
increase in the cutoff productivity level $\left(\varphi^{*}>\varphi_{a}^{*}\right)$ and in the average profit per firm. ${ }^{32}$ The least productive firms with productivity levels between $\varphi_{a}^{*}$ and $\varphi^{*}$ can no longer earn positive profits in the new trade equilibrium and therefore exit. Another selection process also occurs since only the firms with productivity levels above $\varphi_{x}^{*}$ enter the export markets. This export market selection effect and the domestic market selection effect (of firms out of the industry) both reallocate market shares towards more efficient firms and contribute to an aggregate productivity gain. ${ }^{33}$

Inspection of the equations for the equilibrium number of firms ((14) and (22)) reveals that $M<M_{a}$ where $M_{a}$ represents the number of firms in autarky. ${ }^{34}$ Although the number of firms in a country decreases after the transition to trade, consumers in the country still typically enjoy greater product variety $\left(M_{t}=\left(1+p_{x}\right) M>M_{a}\right)$. That is, the decrease in the number of domestic firms following the transition to trade is typically dominated by the number of new foreign exporters. It is nevertheless possible, when the export costs are high, that these foreign firms replace a larger number of domestic firms (if the latter are sufficiently less productive). Although product variety then impacts negatively on welfare, this effect is necessarily dominated by the positive contribution of the aggregate productivity gain. Trade - even though it is costly - necessarily generates a welfare gain (see appendix for proof).

\section{The Reallocation of Market Shares and Profits Across Firms}

I now examine how the impact of trade on individual firms changes with the firm's productivity level. To do this, I track the performance of a firm with productivity $\varphi \geq \varphi_{a}^{*}$ during the transition from autarky to trade. Let $r_{a}(\varphi)>0$ and $\pi_{a}(\varphi) \geq 0$ denote the firm's revenue and profit in autarky. Recall that, in both the closed and open economy equilibria, the aggregate revenue of domestic firms is exogenously given by the country's size $(R=L)$. Hence, $\frac{r_{a}(\varphi)}{R}$ and $\frac{r(\varphi)}{R}$ represent the firm's market share (within the domestic industry) in autarky and in the equilibrium with trade. Additionally, in this equilibrium with trade, $\frac{r_{d}(\varphi)}{R}$ represents the firm's share of its domestic market (since $r_{d}(\varphi)$ is the firm's domestic revenue and $R$ also represents aggregate consumer expenditure in the country). The impact of trade on this firm's market share can be evaluated using the following

\footnotetext{
${ }^{32}$ Recall that the FE curve must be upward sloping and cuts the ZCP curve from below.

${ }^{33}$ Because $\tilde{\varphi}_{t}$ factors in the output lost in export transit (from $\tau$ ), it is possible for $\tilde{\varphi}_{t}$ to be lower than $\tilde{\varphi}_{a}$ when $\tau$ is high and $f_{x}$ is low. It is shown in the appendix that any productivity average that is based on a firm's output "at the factory gate" must be higher in the open economy than in autarky.

${ }^{34}$ Recall that the average profit $\bar{\pi}$ must be higher in the open economy equilibrium.
} 
inequalities (see appendix):

$$
r_{d}(\varphi)<r_{a}(\varphi)<r_{d}(\varphi)+n r_{x}(\varphi), \quad \forall \varphi \geq \varphi^{*}
$$

The first part of the inequality indicates that all firms incur a loss in their share of their domestic market with the transition to trade. A firm who does not export then also incurs a total revenue loss. The second part of the inequality indicates that a firm who exports more than makes up for its loss of domestic sales with export sales and increases its total revenues. Thus, a firm who exports increases its share of industry revenues while a firm who does not export loses market share. $\varphi_{x}^{*}$ is then also the cutoff level that partitions the firms between those who gain and those who lose market share. (The market share of the least productive firms in the autarky equilibrium - with productivity between $\varphi_{a}^{*}$ and $\varphi^{*}-$ drops down to zero as these firms exit.)

Now consider the change in profit earned by a firm with productivity level $\varphi$ during the transition to trade. If the firm does not export in the new trade equilibrium, then it must incur a profit loss, since its revenue, and hence variable profit, is now lower. The direction of the profit change for an exporting firm is not immediately clear since it involves a trade-off between the increase in total revenue (and hence variable profit) and the increase in fixed cost due to the additional export cost. For such a firm $\left(\varphi \geq \varphi_{x}^{*}\right)$, this profit change can be written: ${ }^{35}$

$$
\begin{aligned}
\Delta \pi(\varphi)=\pi(\varphi)-\pi_{a}(\varphi) & =\frac{1}{\sigma}\left(\left[r_{d}(\varphi)+n r_{x}(\varphi)\right]-r_{a}(\varphi)\right)-n f_{x} \\
& =\varphi^{\sigma-1} f\left[\frac{1+n \tau^{1-\sigma}}{\left(\varphi^{*}\right)^{\sigma-1}}-\frac{1}{\left(\varphi_{a}^{*}\right)^{\sigma-1}}\right]-n f_{x}
\end{aligned}
$$

where $\left[\frac{1+n \tau^{1-\sigma}}{\left(\varphi^{*}\right)^{\sigma-1}}-\frac{1}{\left(\varphi_{a}^{*}\right)^{\sigma-1}}\right]$ must be positive since $r_{d}(\varphi)+n r_{x}(\varphi)>r_{a}(\varphi)$ for some $\varphi>0$. The profit change for an exporting firm, $\Delta \pi(\varphi)$, will thus be an increasing function of the firm's productivity level $\varphi$. In addition, this change must be negative for the exporting firm with the cutoff productivity level $\varphi_{x}^{*}:{ }^{36}$ Therefore, there must exist another cutoff productivity level $\varphi^{\dagger}>\varphi_{x}^{*}$ that partitions the firms between those who gain and those who lose profits. Within this group of efficient firms who both export and increase their profits $\left(\varphi>\varphi^{\dagger}\right)$, the profit gain increases with the firm's productivity level. Figure 3 graphically represents the changes in revenue and profits driven by trade.

\footnotetext{
${ }^{35} \mathrm{Using} r_{d}(\varphi)=\left(\frac{\varphi}{\varphi^{*}}\right)^{\sigma-1} \sigma f$ and $r_{a}(\varphi)=\left(\frac{\varphi}{\varphi_{a}^{*}}\right)^{\sigma-1} \sigma f$.

${ }^{36}$ Since $\pi_{x}\left(\varphi_{x}^{*}\right)=0$ and $r_{d}\left(\varphi_{x}^{*}\right)<r_{a}\left(\varphi_{x}^{*}\right)$.
} 
Summarizing these results on the firm level impact of trade by stating that the benefits of trade are not equally spread across firms would be quite an understatement! It was just shown how the exposure to trade generates the type of Darwinian evolution described in the introduction: the most efficient firms thrive and grow - they export and increase both their market share and profits. Some less efficient firms still export and increase their market share but incur a profit loss. Some even less efficient firms remain in the industry but do not export and incur losses of both market share and profit. Finally, the least efficient firms are driven out of the industry.

\section{Why Does Trade Force the Least Productive Firms to Exit?}

The most obvious cause explaining the exit of the least productive domestic firms would be the new competition from the entry of the more productive firms into the domestic market. However, this intuition is incorrect. In order to highlight this point, it is necessary to consider breaking the model's symmetry between opening the economy to import competition and to new export markets. If the current model were amended to allow for the new import competition without introducing any export opportunities, then this trade opening would not induce any distributional changes among firms. With C.E.S. product differentiation, the new import competition affects domestic firms with different productivity levels in similar ways, and translates only into a reduction in aggregate sales for all domestic firms. In equilibrium, this induces a reduction in the number of surviving domestic firms while holding the distribution of firm productivity levels and relative market shares constant.

On the other hand, if the model were amended to allow for the opening of new export markets without any import competition, then distributional changes very similar to those described for the symmetric trade case would occur (and the least productive firms would be forced to exit the industry). When entry into new export markets is costly, then this exposure to trade affects firms with different productivity levels in different ways: the new export markets offer increased profit opportunities only to the more productive firms who can "afford" to pay the export market entry costs. In equilibrium, an increase in the profits of more productive firms relative to less productive firms leads to more entry and a higher cutoff productivity level. It is therefore the "pull" of the export markets, rather than the "push" of import competition that forces the least productive firms to exit. 


\section{The Impact of Trade Liberalization}

The preceding analysis compared the equilibrium outcomes of an economy undergoing a massive change in trade regime from autarky to trade. Very few, if any, of the world's current economies can be considered to operate in an autarky environment. It is therefore reasonable to ask whether an increase in the exposure of an economy to trade will induce the same effects as were previously described for the transition of an economy from autarky. The current model is well-suited to address several different mechanisms that would produce an increase in trade exposure and plausibly correspond to observed decreases in trade costs over time or some specific policies to liberalize trade. The effects of three such mechanisms are investigated: an increase in the number of available trading partners (resulting, for example, from the incorporation of additional countries into a trade bloc) and a decrease in either the fixed or variable trade costs (resulting either from decreases in real costs levels or from multi-lateral agreements to reduce tariffs or non-tariff barriers to trade). These three scenarios involve comparative statics of the open economy equilibrium with respect to $n$, $\tau$, and $f_{x}$. The main impact of the transition from autarky to trade was an increase in aggregate productivity and welfare generated by a reallocation of market shares towards more productive firms (where the least productive firms are forced to exit). I will show that increases in the exposure to trade occurring through any of these mechanisms will generate very similar results: in all cases, the exposure to trade will force the least productive firms to exit and will reallocate market shares from less productive to more productive firms. The increased exposure to trade will also unequivocally deliver welfare gains. ${ }^{37}$

\section{Increase in the Number of Trading Partners}

I first investigate the effects of an increase in $n$. Throughout this comparative static exercise, I use the notation of the open economy equilibrium to describe the old equilibrium with $n$ countries. I then add primes $\left({ }^{\prime}\right)$ to all variables and functions when they pertain to the new equilibrium with $n^{\prime}>n$ countries.

Inspection of equations (21) and (20) defining the new zero cutoff profit condition (as a function of the domestic cutoff $\varphi^{*}$ ) reveals that the ZCP curve will shift up and therefore that both cutoff productivity levels increase with $n: \varphi^{* \prime}>\varphi^{*}$ and $\varphi_{x}^{* \prime}>\varphi_{x}^{*}$. The increase in the number of trading partners thus forces the least productive firms to exit. As was the case with the transition from

\footnotetext{
${ }^{37}$ Formal derivations of all the comparative statics are relegated to the appendix.
} 
autarky, the increased exposure to trade forces all firms to relinquish a portion of their share of their domestic market: $r_{d}(\varphi)<r_{d}(\varphi), \forall \varphi \geq \varphi^{*}$. The less productive firms who do not export (with $\left.\varphi<\varphi_{x}^{* \prime}\right)$ thus incur a revenue and profit loss - and the least productive among them therefore exit. ${ }^{38}$ Again, as was the case with the transition from autarky, the firms who export (with $\varphi \geq \varphi_{x}^{* \prime}$ ) more than make up for their loss of domestic sales with their sales to the new export markets and increase their combined revenues: $r_{d}^{\prime}(\varphi)+n^{\prime} r_{x}(\varphi)>r_{d}(\varphi)+n r_{x}(\varphi)$. Some of these firms nevertheless incur a decrease in profits due to the new fixed export costs, but the most productive firms among this group also enjoy an increase in profits (which is increasing with the firms' productivity level). Thus, both market shares and profits are reallocated towards the more efficient firms. As was the case for the transition from autarky, this reallocation of market shares generates an aggregate productivity gain and an increase in welfare. ${ }^{39}$

\section{Decrease in Trade Costs}

A decrease in the variable trade cost $\tau$ will induce almost identical effects to those just described for the increase in trading partners. The decrease from $\tau$ to $\tau^{\prime}<\tau$ (again I use primes to reference all variables and functions in the new equilibrium) will shift up the ZCP curve and induce an increase in the cutoff productivity level $\varphi^{* \prime}>\varphi^{*}$. The only difference will be that the new export cutoff productivity level $\varphi_{x}^{* \prime}$ will now be below $\varphi_{x}^{*}$. As before, the increased exposure to trade will force the least productive firms to exit, but it will now also generate the entry of new firms into the export market (who did not export with the higher $\tau$ ). The direction of the reallocation of market shares and profits will be identical to those previously described: all firms will lose a portion of their domestic sales, so that the firms who do not export incur both a market share and profit loss. The more productive firms who export more than make up for their loss of domestic sales with their increased export sales, and the most productive firms among this group also increase their profits. As before, the exit of the least productive firms and the market share increase of the most productive firms both contribute to an aggregate productivity gain and an increase in welfare. ${ }^{40}$

\footnotetext{
${ }^{38}$ There is a transitional issue associated with the exporting status of firms with productivity levels between $\varphi_{x}^{*}$ and $\varphi_{x}^{* \prime}$. The loss of export sales to any given country (from $r_{x}(\varphi)$ down to $r_{x}{ }^{\prime}(\varphi)$ ) is such that firms entering with productivity levels between $\varphi_{x}^{*}$ and $\varphi_{x}^{* \prime}$ will not export as the lower variable profit $\frac{r_{x}{ }^{\prime}(\varphi)}{\sigma}$ no longer covers the amortized portion of the entry cost $f_{x}$. On the other hand, incumbent firms with productivity levels in this range have already incurred the sunk export entry cost and have no reason to exit the export markets until they are hit with the bad shock and exit the industry. Eventually, all these incumbent firms exit and no firm with a productivity level in that range will export once the new steady state equilibrium is attained.

${ }^{39}$ As pointed out in note 33 , the productivity average must be based on a firm's output "at the factory gate".

${ }^{40}$ See note $(39)$
} 
A decrease in the fixed export market entry cost $f_{x}$ will induce similar changes in the cutoff levels as the decrease in $\tau$. The increased exposure to trade forces the least productive firms to exit $\left(\varphi^{*}\right.$ rises $)$ and generates entry of new firms into the export market ( $\varphi_{x}^{*}$ decreases). These selection effects both contribute to an aggregate productivity increase if the new exporters are more productive than the average productivity level. Although the less productive firms who do not export incur both a market share and profit loss, the market share and profit reallocations towards the more productive firms, in this case, will not be similar to those for the previous two cases: the decrease in $f_{x}$ will not increase the combined market share or profit of any firm that already exported prior to the change in $f_{x}$ - only new exporters increase their combined sales. However, as in the previous two cases, welfare will necessarily be higher in the new steady state equilibrium. Both types of trade costs decreases described above also help to explain another empirical feature reported by Roberts, Sullivan and Tybout (1995) that some export booms are driven by the entry of new firms into the export markets. ${ }^{41}$

\section{Conclusion}

This paper has described and analyzed a new transmission channel for the impact of trade on industry structure and performance. Since this channel works through intra-industry reallocations across firms, it can only be studied within an industry model that incorporates firm level heterogeneity. Recent empirical work has highlighted the importance of this channel for understanding and explaining the effects of trade on firm and industry performance.

The paper shows how the existence of export market entry costs drastically affects how the impact of trade is distributed across different types of firms. The induced reallocations between these different firms generate changes in a country's aggregate environment that can not be explained by a model based on representative firms. On one hand, the paper shows that the existence of such costs to trade does not affect the welfare-enhancing properties of trade: one of the most robust results of this paper is that increases in a country's exposure to trade lead to welfare gains. On the other hand, the paper shows how the export costs significantly alter the distribution of the gains from trade across firms. In fact, only a portion of the firms - the more efficient ones - reap benefits from trade in the form of gains in market share and profit. Less efficient firms lose both. The exposure to trade, or increases in this exposure, force the least efficient firms out of the indus-

\footnotetext{
${ }^{41}$ Over half of the substantial export growth in Colombian and Mexican manufacturing sectors was generated by the entry of firms into the export markets.
} 
try. These trade-induced reallocations towards more efficient firms explain why trade may generate aggregate productivity gains without necessarily improving the productive efficiency of individual firms. Although increases in the exposure to trade always generates more import competition, the latter is not the root cause behind the exit of the least productive firms. This exit is always driven by the entry of firms in response to the higher relative profits earned by exporters.

Although this model mainly highlights the long-run benefits associated with the trade-induced reallocations within an industry, the reallocation of these resources also obviously entails some short-run costs. It is therefore important to have a model that can predict the impact of trade policy on inter-firm reallocations in order to design accompanying policies that would address issues related to the transition towards a new regime. These policies could help palliate the transitional costs while taking care not to hinder the reallocation process. Of course, the model also clearly indicates that policies that hinder the reallocation process or otherwise interfere with the flexibility of the factor markets may delay or even prevent a country from reaping the full benefits from trade.

\section{References}

Aw, Bee Yan, Sukkyun Chung and Mark J Roberts. 2000. "Productivity and Turnover in the Export Market: Micro-level Evidence from the Republic of Korea and Taiwan (China)." World Bank Economic Review 14:65-90.

Basu, Susanto and John Fernald. 1997. "Aggregate Productivity and Aggregate Technology." International Finance Discussion Paper No. 593.

Bernard, Andrew B and J Bradford Jensen. 1999a. "Exceptional Exporter Performance: Cause, Effect, or Both?" Journal of International Economics 47:1-25.

Bernard, Andrew B and J Bradford Jensen. 1999b. "Exporting and Productivity." NBER Working Paper No. 7135.

Bernard, Andrew B., Jonathan Eaton, J. Bradford Jenson and Samuel Kortum. 2000. "Plants and Productivity in International Trade." NBER Working Paper No. 7688.

Brooks, Eileen L. 2001. "Why Don’t Firms Export More?" Mimeo, University of California SantaCruz.

Clerides, Sofronis K, Saul Lach and James R. Tybout. 1998. "Is Learning by Exporting Important? Micro-dynamic Evidence from Colombia, Mexico, and Morocco." The Quarterly Journal of Economics 113:903-47.

Davis, Stephen and John Haltiwanger. 1999. Gross Job Flows. In Handbook of Labor Economics: Voume 3B, ed. Orley Ashenfelter and David Card. North Holland pp. 2711-2805. 
Dixit, Avinash and Joseph Stiglitz. 1977. "Monopolistic Competition and Optimum Product Diversity." American Economic Review 67:297-308.

Feldman, Mark and Chirstian Gilles. 1985. "An Expository Note on Individual Risk without Aggregate Uncertainty." Journal of Economic Theory 35:26-32.

Foster, Lucia, John Haltiwanger and C.J. Krizan. 1998. "Aggregate Productivity Growth: Lessons from Microeconomic Evidence." NBER Working Paper No. 6803.

Haltiwanger, John. 1997. "Measuring and Analyzing Aggregate Fluctuations: The Importance of Building from Microeconomic Evidence." Federal Reserve Bank of St. Louis Economic Review pp. $55-77$.

Hopenhayn, Hugo. 1992a. "Entry, Exit, and Firm Dynamics in Long Run Equilibrium." Econometrica 60:1127-1150.

Hopenhayn, Hugo. 1992b. "Exit, Selection, and the Value of Firms." Journal of Economic Dynamics and Control 16:621-653.

Jovanovic, Boyan. 1982. "Selection and the Evolution of Industry." Econometrica 50:649-70.

Krugman, Paul. 1979. "Increasing Returns, Monopolistic Competition, and International Trade." Journal of International Economics 9:469-479.

Krugman, Paul. 1980. "Scale Economies, Product Differentiation, and the Pattern of Trade." American Economic Review 70:950-959.

Levinsohn, James. 1999. "Employment Responses to International Liberalization in Chile." Journal of International Economics 47:321-44.

Montagna, Catia. 1995. "Monopolistic Competition with Firm-Specific Costs." Oxford Economic Papers 47:318-28.

Olley, Steven and Ariel Pakes. 1996. "The Dynamics of Productivity in the Telecommunications Equipment Industry." Econometrica 64:1263-97.

Pavcnik, Nina. 2002. "Trade Liberalization, Exit, and Productivity Improvements: Evidence from Chilean Plants." The Review of Economic Studies 69:245-276.

Roberts, Mark J and James R Tybout. 1997a. "The Decision to Export in Colombia: An Empirical Model of Entry with Sunk Costs." American Economic Review 87:545-64.

Roberts, Mark and James Tybout. 1997b. What Makes Exports Boom? The World Bank.

Roberts, Mark and James Tybout, eds. 1996. Industrial Evolution in Developing Countries. Oxford University Press.

Roberts, Mark, Theresa Sullivan and James Tybout. 1995. "Micro-Foundations of Export Booms." World Bank, mimeo .

Tybout, James R. 2002. Plant and Firm-Level Evidence on New Trade Theories. In Handbook of International Economics, ed. James Harrigan. Vol. 38 Basil-Blackwell.

Tybout, James R. and Daniel Westbrook. 1995. "Trade Liberalization and the Dimensions of Efficiency Change in Mexican Manufacturing Industries." Journal of International Economics $39: 53-78$. 


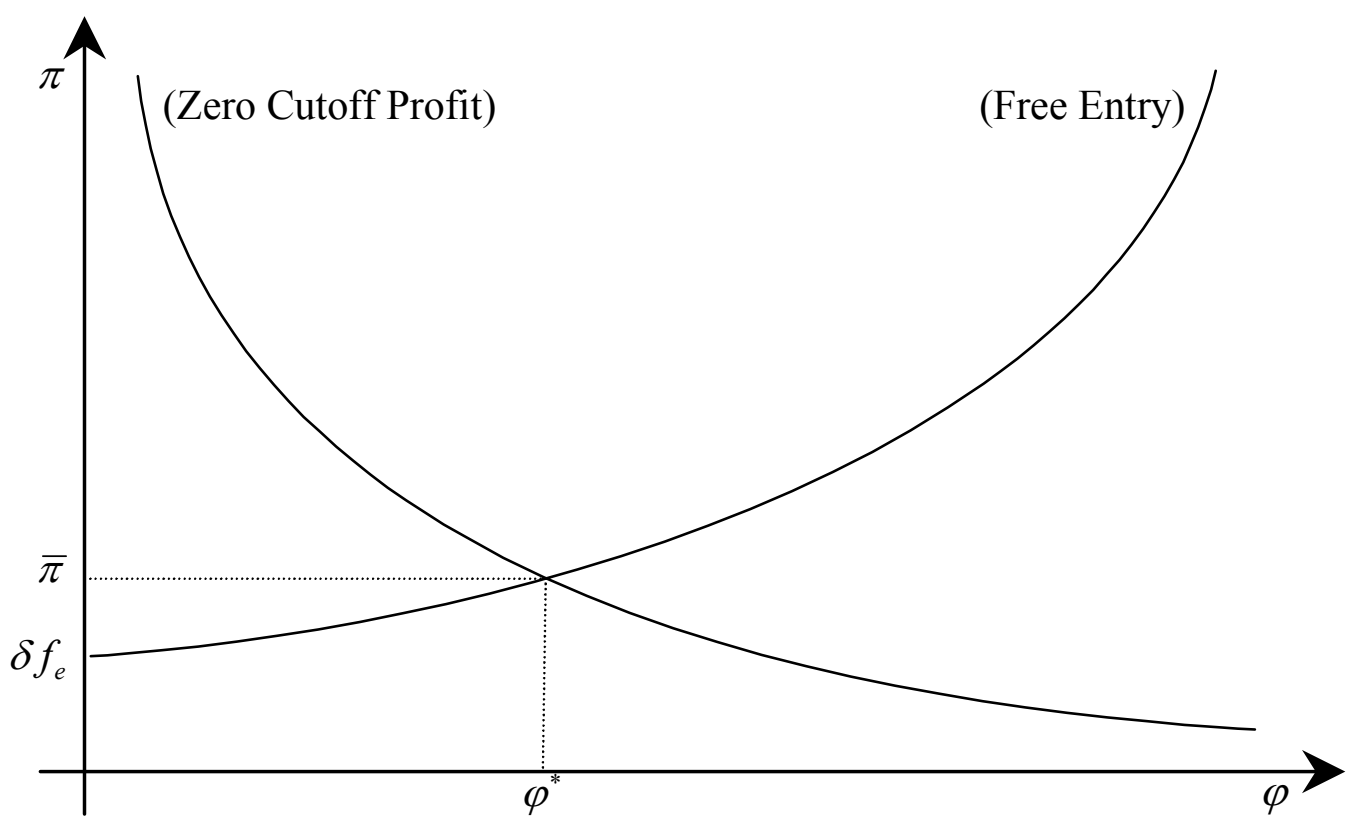

Figure 1: Determination of the Equilibrium Cutoff $\varphi^{*}$ and Average Profit $\bar{\pi}$

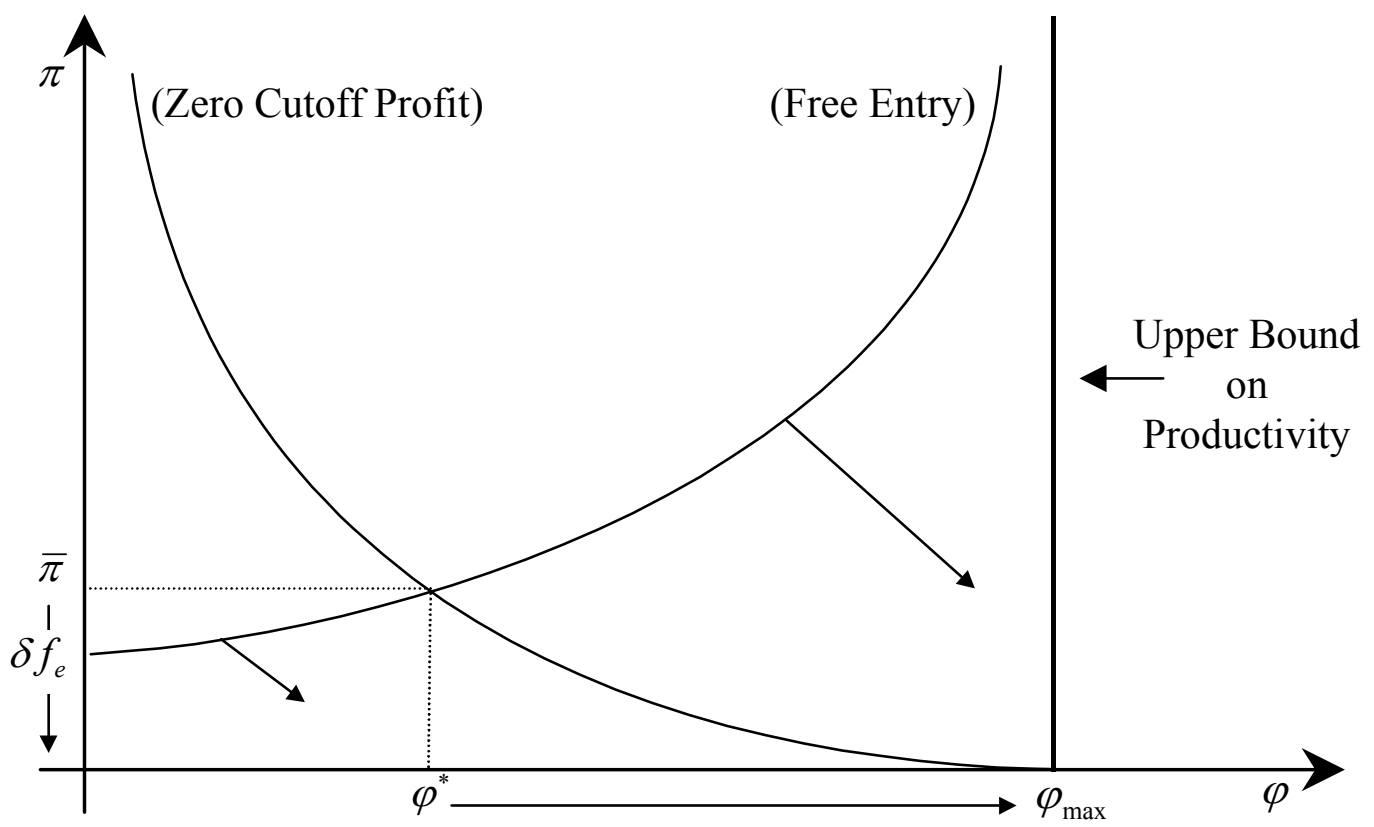

Figure 2: Representative Firms as a Limiting Equilibrium When $f_{e} \rightarrow 0$. 


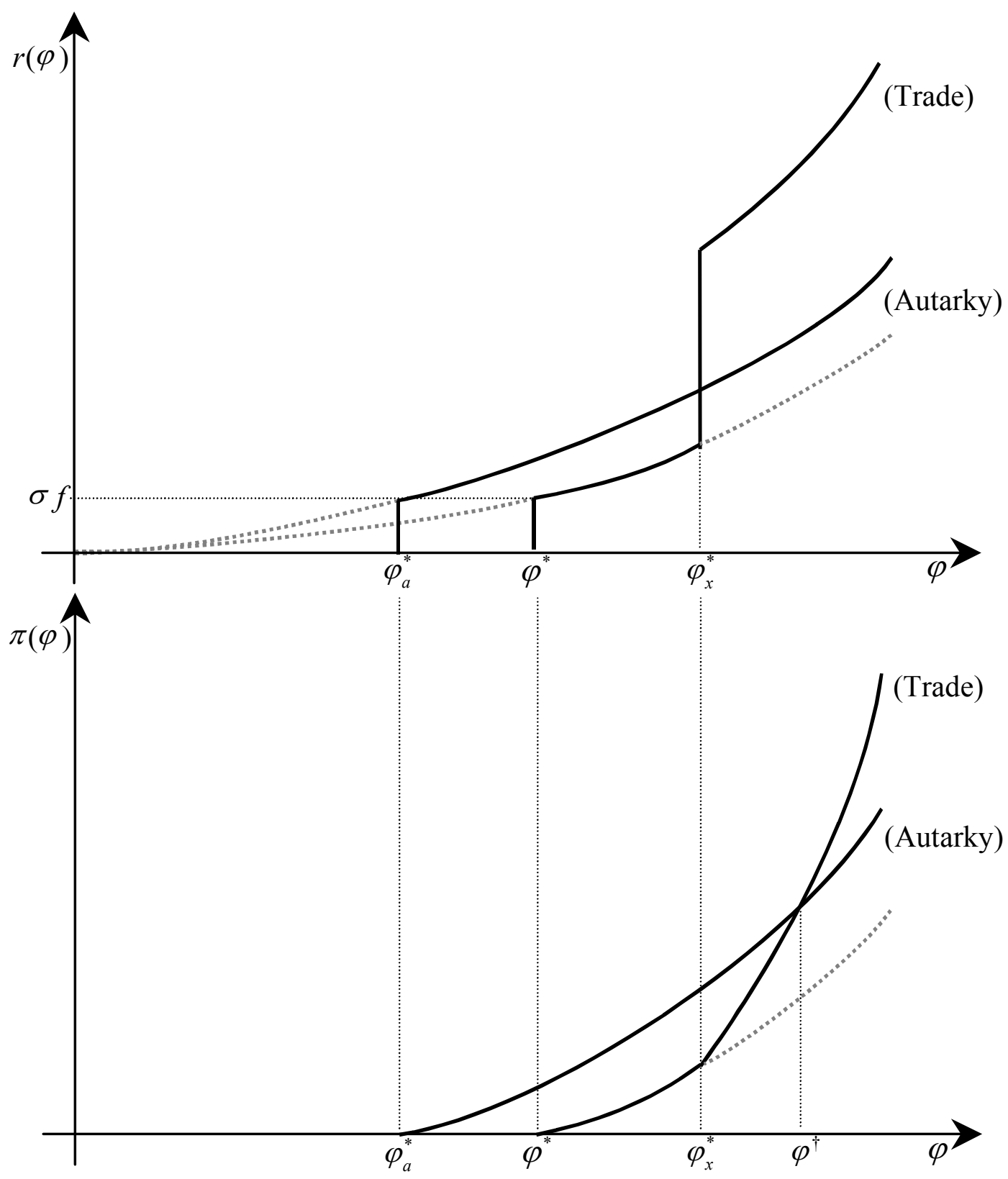

Figure 3: The reallocation of market shares and profits. 


\section{Appendix}

\section{A Aggregation Conditions in the Closed Economy}

Using the definition of $\tilde{\varphi}$ in (7), the aggregation conditions relating the aggregate variables to the number of firms $M$ and aggregate productivity level $\tilde{\varphi}$ are derived:

$$
\begin{array}{rlr}
Q & =\left[\int_{0}^{\infty} q(\varphi)^{\rho} M \mu(\varphi) d \varphi\right]^{1 / \rho} & \text { by definition of } Q \equiv U \\
& =\left[\int_{0}^{\infty} q(\tilde{\varphi})^{\rho}\left(\frac{\varphi}{\tilde{\varphi}}\right)^{\sigma \rho} M \mu(\varphi) d \varphi\right]^{1 / \rho} & \\
& =M^{1 / \rho} q(\tilde{\varphi})\left[\frac{1}{\tilde{\varphi}^{\sigma-1}} \int_{0}^{\infty} \varphi^{\sigma-1} \mu(\varphi) d \varphi\right]^{1 / \rho} \\
& =M^{1 / \rho} q(\tilde{\varphi}), &
\end{array}
$$

and using the definition of $R$ and $\Pi$ as aggregate revenue and profit,

$$
\begin{aligned}
R & =\int_{0}^{\infty} r(\varphi) M \mu(\varphi) d \varphi \\
& =\int_{0}^{\infty} r(\tilde{\varphi})\left(\frac{\varphi}{\tilde{\varphi}}\right)^{\sigma-1} M \mu(\varphi) d \varphi \\
& =\operatorname{Mr}(\tilde{\varphi}) \frac{1}{\tilde{\varphi}^{\sigma-1}} \int_{0}^{\infty} \varphi^{\sigma-1} \mu(\varphi) d \varphi \\
& =\operatorname{Mr}(\tilde{\varphi}),
\end{aligned}
$$

$$
\begin{aligned}
\Pi & =\int_{0}^{\infty} \pi(\varphi) M \mu(\varphi) d \varphi \\
& =\int_{0}^{\infty}\left[\frac{r(\varphi)}{\sigma} f\right] M \mu(\varphi) d \varphi \\
& =\frac{1}{\sigma} \int_{0}^{\infty} r(\varphi) M \mu(\varphi) d \varphi-M f \\
& =M\left[\frac{r(\tilde{\varphi})}{\sigma} f\right] \\
& =M \pi(\tilde{\varphi}) .
\end{aligned}
$$

\section{B Closed Economy Equilibrium}

\section{Existence and Uniqueness of the Equilibrium Cutoff Level $\varphi^{*}$}

Following is a proof that the FE condition, $\bar{\pi}=\frac{\delta f_{e}}{1-G\left(\varphi^{*}\right)}$, and ZCP condition, $\bar{\pi}=f k\left(\varphi^{*}\right)$, in (12) identify a unique cutoff level $\varphi^{*}$ and that the ZCP curve cuts the FE curve from above in $(\varphi, \pi)$ space. I do this by showing that $[1-G(\varphi)] k(\varphi)$ is monotonically decreasing from infinity to zero on $(0, \infty)$. (This is a sufficient condition for both properties.) Recall that $k(\varphi)=\left(\frac{\tilde{\varphi}(\varphi)}{\varphi}\right)^{\sigma-1}-1$ where

$$
\tilde{\varphi}(\varphi)^{\sigma-1}=\frac{1}{1-G(\varphi)} \int_{\varphi}^{\infty} \xi^{\sigma-1} g(\xi) d \xi
$$


as defined in (9). Differentiating with respect to $\varphi$ yields

$$
\frac{\partial \tilde{\varphi}(\varphi)^{\sigma-1}}{\partial \varphi}=\frac{g(\varphi)}{1-G(\varphi)}\left[\tilde{\varphi}(\varphi)^{\sigma-1}-\varphi^{\sigma-1}\right]
$$

and hence

$$
\begin{aligned}
k^{\prime}(\varphi) & =\frac{g(\varphi)}{1-G(\varphi)}\left[\left(\frac{\tilde{\varphi}(\varphi)}{\varphi}\right)^{\sigma-1}-1\right]-\left(\frac{\tilde{\varphi}(\varphi)}{\varphi}\right)^{\sigma-1} \frac{\sigma-1}{\varphi} \\
& =\frac{k(\varphi) g(\varphi)}{1-G(\varphi)}-\frac{(\sigma-1)[k(\varphi)+1]}{\varphi} .
\end{aligned}
$$

Define

$$
j(\varphi)=[1-G(\varphi)] k(\varphi)
$$

Then its derivative and elasticity are given by:

$$
\begin{aligned}
j^{\prime}(\varphi) & =-\frac{1}{\varphi}(\sigma-1)[1-G(\varphi)][k(\varphi)+1]<0, \\
\frac{j^{\prime}(\varphi) \varphi}{j(\varphi)} & =-(\sigma-1)\left(1+\frac{1}{k(\varphi)}\right)<-(\sigma-1) .
\end{aligned}
$$

Since $j(\varphi)$ is non-negative and its elasticity with respect to $\varphi$ is negative and bounded away from zero, $j(\varphi)$ must be decreasing to zero as $\varphi$ goes to infinity. Furthermore, $\lim _{\varphi \rightarrow 0} j(\varphi)=\infty$ since $\lim _{\varphi \rightarrow 0} k(\varphi)=\infty$. Therefore, $j(\varphi)=[1-G(\varphi)] k(\varphi)$ decreases from infinity to zero on $(0, \infty)$.

\section{Comparative Statics}

Several of the comparative statics will use the property that welfare per worker can be written as a function of only the cutoff level $\varphi^{*}: 42$

$$
W=M^{\frac{1}{\sigma-1}} \rho \tilde{\varphi}=L^{\frac{1}{\sigma-1}} \rho\left(\frac{1}{\sigma f}\right)^{\frac{1}{\sigma-1}} \varphi^{*}
$$

Note that the property that welfare decreases with a rise in the entry cost $f_{e}$ is then immediately obtained as it was shown that $\varphi^{*}$ decreases in that situation. The direction of the welfare change induced by a rise in the overhead production cost is not immediately obvious as $f$ enters into the welfare equation in (B.5). (Recall that a rise in $f$ induces an increase in $\varphi^{*}$.) The direction of the

${ }^{42}$ using the relationship $\left(\frac{\tilde{\varphi}}{\varphi^{*}}\right)^{\sigma-1}=\frac{r(\tilde{\varphi})}{r\left(\varphi^{*}\right)}=\frac{R / M}{\sigma f}=\frac{L}{M} \frac{1}{\sigma f}$. 
welfare change therefore depends on the direction of the change in $\left(\frac{1}{f}\right)^{\frac{1}{\sigma-1}} \varphi^{*}$, or alternatively, on the direction of the change in $\frac{\left(\varphi^{*}\right)^{\sigma-1}}{f}$.

Proof that $\frac{\left(\varphi^{*}\right)^{\sigma-1}}{f}$ Decreases when $f$ Increases

The FE and ZCP equilibrium conditions for $\varphi^{*}$ imply $\bar{\pi}=f k\left(\varphi^{*}\right)=\frac{\delta f_{e}}{1-G\left(\varphi^{*}\right)}$, and thus

$$
f j\left(\varphi^{*}\right)=\delta f_{e}
$$

using the definition for $j(\varphi)$ in (B.2). Differentiating (B.6) with respect to $f$ yields:

$$
j\left(\varphi^{*}\right)+f j^{\prime}\left(\varphi^{*}\right) \frac{\partial \varphi^{*}}{\partial f}=0 \Longleftrightarrow \frac{\partial \varphi^{*}}{\partial f} \frac{f}{\varphi^{*}}=-\frac{j\left(\varphi^{*}\right)}{\varphi^{*} j^{\prime}\left(\varphi^{*}\right)}<\frac{1}{\sigma-1}
$$

using (B.4). The differential change in $\frac{\left(\varphi^{*}\right)^{\sigma-1}}{f}$ is then given by

$$
\begin{aligned}
\frac{\partial\left(\frac{\left(\varphi^{*}\right)^{\sigma-1}}{f}\right)}{\partial f} & =\frac{\left(\varphi^{*}\right)^{\sigma-1}}{f}\left[(\sigma-1) \frac{\partial \varphi^{*}}{\partial f} \frac{f}{\varphi^{*}}-1\right] \\
& <0 .
\end{aligned}
$$

Hence, $\frac{\left(\varphi^{*}\right)^{\sigma-1}}{f}$ decreases when $f$ increases. An increase in $f$ therefore generates a welfare loss.

\section{Open Economy Equilibrium}

\section{Aggregate Labor Resources Used to Cover the Export Costs}

It was asserted in note 25 that the ratio of new exporters to all exporters was $\delta$, and hence that the aggregate labor resources used to cover the export cost did not depend on its representation as either a one time sunk entry cost or a per-period fixed cost. As before, let $M_{e}$ denote the mass of all new entrants. The ratio of new exporters to all exporters is then $\frac{p_{x} p_{i n} M_{e}}{p_{x} M}=\frac{p_{x} p_{i n} M_{e}}{p_{x} M}$. This ratio must be equal to $\delta$ as the aggregate stability condition for the equilibrium ensures that $p_{i n} M_{e}=\delta M$.

\section{Existence and Uniqueness of the Equilibrium Cutoff Level $\varphi^{*}$}

Following is a proof that the FE condition, $\bar{\pi}=\frac{\delta f_{e}}{1-G\left(\varphi^{*}\right)}$, and the new ZCP condition, $\bar{\pi}=f k\left(\varphi^{*}\right)+$ $p_{x} n f_{x} k\left(\varphi_{x}^{*}\right)$, in (21) identify a unique cutoff level $\varphi^{*}$ and that the new ZCP curve cuts the FE curve 
from above in $(\varphi, \pi)$ space. These conditions imply $\frac{\delta f_{e}}{1-G\left(\varphi^{*}\right)}=f k\left(\varphi^{*}\right)+p_{x} n f_{x} k\left(\varphi_{x}^{*}\right)$, or

$$
f j\left(\varphi^{*}\right)+n f_{x} j\left(\varphi_{x}^{*}\right)=\delta f_{e}
$$

where $\varphi_{x}^{*}=\tau\left(\frac{f_{x}}{f}\right)^{\frac{1}{\sigma-1}} \varphi^{*}$ is implicitly defined as a function of $\varphi^{*}$ (see $(20)$ ). Since $j(\varphi)$ is decreasing from infinity to zero on $(0, \infty)$, the left hand side in (C.1) must also monotonically decrease from infinity to zero on $(0, \infty)$. Therefore, (C.1) identifies a unique cutoff level $\varphi^{*}$ and the new ZCP curve must cut the FE curve from above.

\section{The Impact of Trade}

\section{Welfare}

Using (B.5), welfare per worker in autarky can be written:

$$
W_{a}=M_{a}^{\frac{1}{\sigma-1}} \rho \tilde{\varphi}_{a}=L^{\frac{1}{\sigma-1}} \rho\left(\frac{1}{\sigma f}\right)^{\frac{1}{\sigma-1}} \varphi_{a}^{*} .
$$

Similarly, welfare in the open economy can be written as a function of only the cutoff productivity level (see (18)): ${ }^{43}$

$$
W=M_{t}^{\frac{1}{\sigma-1}} \rho \tilde{\varphi}_{t}=L^{\frac{1}{\sigma-1}} \rho\left(\frac{1}{\sigma f}\right)^{\frac{1}{\sigma-1}} \varphi^{*} .
$$

Since $\varphi^{*}>\varphi_{a}^{*}$, welfare in the open economy must be higher than in autarky: $W>W_{a}$.

\section{Reallocations}

Proof that $r_{d}(\varphi)<r_{d}(\varphi)<r_{d}(\varphi)+n r_{x}(\varphi)=\left(1+n \tau^{1-\sigma}\right) r_{d}(\varphi)$

Recall that $r_{a}(\varphi)=\left(\frac{\varphi}{\varphi_{a}^{*}}\right)^{\sigma-1} \sigma f \quad\left(\forall \varphi \geq \varphi_{a}^{*}\right)$ in autarky and that $r_{d}(\varphi)=\left(\frac{\varphi}{\varphi^{*}}\right)^{\sigma-1} \sigma f \quad\left(\forall \varphi \geq \varphi^{*}\right)$ in the open economy equilibrium. This immediately yields $r_{d}(\varphi)<r_{a}(\varphi)$ since $\varphi^{*}>\varphi_{a}^{*}$. The second inequality is a direct consequence of another comparative static involving $\tau$. It is shown in a following section that $\left(1+n \tau^{1-\sigma}\right) r_{d}(\varphi)$ decreases as $\tau$ increases. Since the autarky equilibrium is obtained as the limiting equilibrium as $\tau$ increases to infinity, $r_{a}(\varphi)=\lim _{\tau \rightarrow+\infty} r_{d}(\varphi)=$ $\lim _{\tau \rightarrow+\infty}\left[\left(1+n \tau^{1-\sigma}\right) r_{d}(\varphi)\right]$. Therefore, $r_{a}(\varphi)<\left(1+n \tau^{1-\sigma}\right) r_{d}(\varphi)$ for any finite $\tau$.

${ }^{43}$ using $\left(\frac{\tilde{\varphi}_{t}}{\varphi^{*}}\right)^{\sigma-1}=\frac{r_{d}\left(\tilde{\varphi}_{t}\right)}{r_{d}\left(\varphi^{*}\right)}=\frac{R / M_{t}}{\sigma f}=\frac{L}{M_{t}} \frac{1}{\sigma f}$. 


\section{Aggregate Productivity}

It was pointed out in the paper that aggregate productivity $\tilde{\varphi}_{t}$ in the open economy may not be higher than $\tilde{\varphi}_{a}$ due to the effect of the output loss incurred in export transit. It was then claimed that a productivity average based on a measure of output "at the factory gate" would always be higher in the open economy. Define

$$
\Phi=h^{-1}\left(\frac{1}{R} \int_{0}^{\infty} r(\varphi) h(\varphi) g(\varphi) d \varphi\right)
$$

as such an average where $h($.$) is any increasing function. The only condition imposed on this average$ involves the use of the firms' combined revenues as weights. ${ }^{44}$ Let $\Phi_{a}=h^{-1}\left(\frac{1}{R} \int_{0}^{\infty} r_{a}(\varphi) h(\varphi) g(\varphi) d \varphi\right)$ represent this productivity average in autarky. Then $\Phi$ must be greater than $\Phi_{a}-$ for any increasing function $h($.$) - as the distribution \frac{r(\varphi) g(\varphi)}{R}$ first order stochastically dominates the distribution $\frac{r_{a}(\varphi) g(\varphi)}{R}: \int_{o}^{\varphi} r(\xi) g(\xi) d \xi \leq \int_{o}^{\varphi} r_{a}(\xi) g(\xi) d \xi \quad \forall \varphi$ (and the inequality is strict $\left.\forall \varphi>\varphi_{a}^{*}\right) .{ }^{45}$

\section{E The Impact of Trade Liberalization}

\section{Changes in the cutoff levels}

These comparative statics are all derived from the equilibrium condition for the cutoff levels (C.1) and the implicit definition of $\varphi_{x}^{*}$ as a function of $\varphi^{*}$ in $(20)$.

\section{Increase in $n$}

Differentiating (C.1) with respect to $n$ and using $\frac{\partial \varphi_{x}^{*}}{\partial n}=\frac{\varphi_{x}^{*}}{\varphi^{*}} \frac{\partial \varphi^{*}}{\partial n}$ from (20) yields:

$$
\frac{\partial \varphi^{*}}{\partial n}=\frac{-f_{x} \varphi^{*} j\left(\varphi_{x}^{*}\right)}{f \varphi^{*} j^{\prime}\left(\varphi^{*}\right)+n f_{x} \varphi_{x}^{*} j^{\prime}\left(\varphi_{x}^{*}\right)}
$$

Hence $\frac{\partial \varphi^{*}}{\partial n}>0$ and $\frac{\partial \varphi_{x}^{*}}{\partial n}>0$ since $j^{\prime}(\varphi)<0 \forall \varphi$ (see (B.4)).

\section{Decrease in $\tau$}

Differentiating (C.1) with respect to $\tau$ and using $\frac{\partial \varphi_{x}^{*}}{\partial \tau}=\frac{\varphi_{x}^{*}}{\tau}+\frac{\varphi_{x}^{*}}{\varphi^{*}} \frac{\partial \varphi^{*}}{\partial \tau}$ from (20) yields:

$$
\frac{\partial \varphi^{*}}{\partial \tau}=-\frac{\varphi^{*}}{\tau} \frac{n f_{x} j^{\prime}\left(\varphi_{x}^{*}\right) \varphi_{x}^{*}}{f \varphi^{*} j^{\prime}\left(\varphi^{*}\right)+n f_{x} \varphi_{x}^{*} j^{\prime}\left(\varphi_{x}^{*}\right)} .
$$

\footnotetext{
${ }^{44}$ This is the standard way of computing industry productivity averages in empirical work.

${ }^{45}$ This result is a direct consequence of the marker share re-allocation result.
} 
Hence $\frac{\partial \varphi^{*}}{\partial \tau}<0$ (since $\left.j^{\prime}(\varphi)<0 \forall \varphi\right)$ and $\frac{\partial \varphi_{x}^{*}}{\partial \tau}=-\frac{f j^{\prime}\left(\varphi^{*}\right)}{n f_{x} j^{\prime}\left(\varphi_{x}^{*}\right)} \frac{\partial \varphi^{*}}{\partial \tau}>0$.

Decrease in $f_{x}$

Differentiating (C.1) with respect to $f_{x}$ and using $\frac{\partial \varphi_{x}^{*}}{\partial f_{x}}=\frac{\partial \varphi^{*}}{\partial f_{x}} \frac{\varphi_{x}^{*}}{\varphi^{*}}+\frac{1}{\sigma-1} \frac{\varphi_{x}^{*}}{f_{x}}$ from $(20)$ and $j^{\prime}\left(\varphi_{x}^{*}\right) \varphi_{x}^{*}=$ $-(\sigma-1)\left(j\left(\varphi_{x}^{*}\right)+\left[1-G\left(\varphi_{x}^{*}\right)\right]\right)$ from (B.2) and (B.4) yields:

$$
\frac{\partial \varphi^{*}}{\partial f_{x}}=\frac{n\left[1-G\left(\varphi_{x}^{*}\right)\right]}{f j^{\prime}\left(\varphi^{*}\right)+n f_{x} j^{\prime}\left(\varphi_{x}^{*}\right)\left(\varphi_{x}^{*} / \varphi^{*}\right)}
$$

Hence, $\frac{\partial \varphi^{*}}{\partial f_{x}}<0\left(\right.$ since $\left.j^{\prime}(\varphi)<0 \forall \varphi\right)$ and $\frac{\partial \varphi_{x}^{*}}{\partial f_{x}}=\frac{-1}{n f_{x} j^{\prime}\left(\varphi_{x}^{*}\right)}\left[n j\left(\varphi_{x}^{*}\right)+f j^{\prime}\left(\varphi^{*}\right) \frac{\partial \varphi^{*}}{\partial f_{x}}\right]>0$.

\section{Welfare}

Recall from (D.1) that welfare per worker is given by $W=L^{\frac{1}{\sigma-1}} \rho\left(\frac{1}{\sigma f}\right)^{\frac{1}{\sigma-1}} \varphi^{*}$. Welfare must therefore rise with increases in $n$ and decreases in $f_{x}$ or $\tau$ since all of these changes induce an increase in the cutoff productivity level $\varphi^{*}$.

\section{Re-allocations of Market Shares}

Recall that $r_{d}(\varphi)=\left(\frac{\varphi}{\varphi^{*}}\right)^{\sigma-1} \sigma f \quad\left(\forall \varphi \geq \varphi^{*}\right)$ in the new open economy equilibrium. $r_{d}(\varphi)$ therefore decreases with increases in $n$ and decreases in $f_{x}$ or $\tau$ since all of these changes induce an increase in the cutoff productivity level $\varphi^{*}$. Thus $r_{d}^{\prime}(\varphi)<r_{d}(\varphi) \quad \forall \varphi \geq \varphi^{*}$ whenever $n^{\prime}>n, \tau^{\prime}<\tau$, or $f_{x}^{\prime}<f_{x}\left(\right.$ since $\left.\varphi^{* \prime}>\varphi^{*}\right)$.

The direction of the change in combined domestic and export sales, $r_{d}(\varphi)+n r_{x}(\varphi)=\left(1+n \tau^{1-\sigma}\right) r_{d}(\varphi)$, will depend on the direction of the change in $\frac{1+n \tau^{1-\sigma}}{\left(\varphi^{*}\right)^{\sigma-1}}$. It is therefore clear that a firm's combined sales will decrease in the same proportion as its domestic sales when $f_{x}$ decreases since $1+n \tau^{1-\sigma}$ will remain constant. On the other hand, it is now shown that these combined sales will increase when $n$ increases or $\tau$ decreases as $\frac{1+n \tau^{1-\sigma}}{\left(\varphi^{*}\right)^{\sigma-1}}$ will then increase: 
Increase in $n$

From (E.1),

$$
\begin{aligned}
\frac{\partial \varphi^{*}}{\partial n} \frac{1}{\varphi^{*}} & =-\left[\frac{f}{f_{x}} \frac{\varphi^{*} j^{\prime}\left(\varphi^{*}\right)}{j\left(\varphi_{x}^{*}\right)}+n \frac{\varphi_{x}^{*} j^{\prime}\left(\varphi_{x}^{*}\right)}{j\left(\varphi_{x}^{*}\right)}\right]^{-1} \\
& =-\left[\tau^{\sigma-1} \frac{\left(\varphi^{*}\right)^{\sigma-1} j\left(\varphi^{*}\right)}{\left(\varphi_{x}^{*}\right)^{\sigma-1} j\left(\varphi_{x}^{*}\right)} \frac{\varphi^{*} j^{\prime}\left(\varphi^{*}\right)}{j\left(\varphi^{*}\right)}+n \frac{\varphi_{x}^{*} j^{\prime}\left(\varphi_{x}^{*}\right)}{j\left(\varphi_{x}^{*}\right)}\right]^{-1} \quad \text { (using (20)) } \\
& <\left[(\sigma-1)\left(\tau^{\sigma-1}+n\right)\right]^{-1}
\end{aligned}
$$

since $-\frac{\varphi j^{\prime}(\varphi)}{j(\varphi)}>\sigma-1 \quad \forall \varphi($ see $(\mathrm{B} .4))$ and $\frac{\left(\varphi^{*}\right)^{\sigma-1} j\left(\varphi^{*}\right)}{\left(\varphi_{x}^{*}\right)^{\sigma-1} j\left(\varphi_{x}^{*}\right)}>1 .{ }^{46}$ Hence,

$$
\begin{aligned}
\frac{\partial\left[\frac{1+n \tau^{1-\sigma}}{\left(\varphi^{*}\right)^{\sigma-1}}\right]}{\partial n} & =\frac{1+n \tau^{1-\sigma}}{\left(\varphi^{*}\right)^{\sigma-1}}\left[\frac{1}{\tau^{\sigma-1}+n}-(\sigma-1) \frac{\partial \varphi^{*}}{\partial n} \frac{1}{\varphi^{*}}\right] \\
& >0
\end{aligned}
$$

Decrease in $\tau$

From (E.2),

$$
\begin{aligned}
-\frac{\partial \varphi^{*}}{\partial \tau} \frac{\tau}{\varphi^{*}} & =\left[\frac{f}{n f_{x}} \frac{\varphi^{*} j^{\prime}\left(\varphi^{*}\right)}{\varphi_{x}^{*} j^{\prime}\left(\varphi_{x}^{*}\right)}+1\right]^{-1} \\
& =\left[\frac{f}{n f_{x}} \frac{\left[1-G\left(\varphi^{*}\right)\right]\left[k\left(\varphi^{*}\right)+1\right]}{\left[1-G\left(\varphi_{x}^{*}\right)\right]\left[k\left(\varphi_{x}^{*}\right)+1\right]}+1\right]^{-1} \\
& =\left[\frac{f}{n f_{x}}\left(\frac{\varphi_{x}^{*}}{\varphi^{*}}\right)^{\sigma-1} \frac{\int_{\varphi^{*}}^{\infty} \xi^{\sigma-1} g(\xi) d \xi}{\int_{\varphi_{x}^{*}}^{\infty} \xi^{\sigma-1} g(\xi) d \xi}+1\right]^{-1} \\
& =\left[\frac{\tau^{\sigma-1}}{n} \frac{\int_{\varphi^{*}}^{\infty} \xi^{\sigma-1} g(\xi) d \xi}{\int_{\varphi_{x}^{*}}^{\infty} \xi^{\sigma-1} g(\xi) d \xi}+1\right]^{-1} \\
& <\left[\frac{\tau^{\sigma-1}}{n}+1\right]^{-1}
\end{aligned}
$$

\footnotetext{
${ }^{46}$ Note that $\varphi^{\sigma-1} j(\varphi)$ must be a decreasing function of $\varphi$ since its elasticity with respect to $\varphi$ is $(\sigma-1)+\frac{\varphi j^{\prime}(\varphi)}{j(\varphi)}<0$.
} 
since $\frac{\int_{\varphi^{*}}^{\infty} \xi^{\sigma-1} g(\xi) d \xi}{\int_{\varphi_{x}^{*}}^{\infty} \xi^{\sigma-1} g(\xi) d \xi}>1$ as $\varphi^{*}<\varphi_{x}^{*}$. Hence,

$$
\begin{aligned}
\frac{\partial\left[\frac{1+n \tau^{1-\sigma}}{\left(\varphi^{*}\right)^{\sigma-1}}\right]}{\partial \tau} & =\frac{1+n \tau^{1-\sigma}}{\left(\varphi^{*}\right)^{\sigma-1} \tau}\left[\frac{(1-\sigma) n \tau^{1-\sigma}}{1+n \tau^{1-\sigma}}-(\sigma-1) \frac{\partial \varphi^{*}}{\partial \tau} \frac{\tau}{\varphi^{*}}\right] \\
& =\frac{1+n \tau^{1-\sigma}}{\left(\varphi^{*}\right)^{\sigma-1} \tau}(\sigma-1)\left[-\frac{\partial \varphi^{*}}{\partial \tau} \frac{\tau}{\varphi^{*}}-\left(\frac{\tau^{\sigma-1}}{n}+1\right)^{-1}\right] \\
& <0 .
\end{aligned}
$$

\section{Re-allocations of Profits}

Increase in $n$

All surviving firms who do not export (with $\varphi<\varphi_{x}^{* \prime}$ ) must incur a profit loss since their profits from domestic sales decrease $\left(r_{d}^{\prime}(\varphi)<r_{d}(\varphi)\right)$ and those who would have exported previously (with the lower $n$ ) further lose any profits from exporting. Similarly, the firm with productivity level $\varphi=\varphi_{x}^{* \prime}$ also incurs a profit loss (although the firm exports, it gains zero additional profits from doing so and still incurs the loss in domestic profits). The profit change for all exporting firms (with $\varphi \geq \varphi_{x}^{* \prime}$ ) can be written:

$$
\begin{aligned}
\Delta \pi(\varphi) & =\pi^{\prime}(\varphi)-\pi(\varphi) \\
& =\frac{1}{\sigma}\left[r^{\prime}(\varphi)-r(\varphi)\right]-\left(n^{\prime}-n\right) f_{x} \\
& =\varphi^{\sigma-1} f\left[\frac{1+n^{\prime} \tau^{1-\sigma}}{\left(\varphi^{* \prime}\right)^{\sigma-1}}-\frac{1+n \tau^{1-\sigma}}{\left(\varphi^{*}\right)^{\sigma-1}}\right]-\left(n^{\prime}-n\right) f_{x}
\end{aligned}
$$

This profit change increases without bound with $\varphi$ and will be positive for all $\varphi$ above a cutoff level $\varphi^{\dagger}>\varphi_{x}^{* \prime}{ }^{47}$

\section{Decrease in $\tau$}

As was the case with the increase in $n$, the least productive firms who do not export (with $\varphi<\varphi_{x}^{* \prime}$ ) incur both a revenue and profit loss. There now exists a new category of firms with intermediate productivity levels $\left(\varphi_{x}^{* \prime} \leq \varphi<\varphi_{x}^{*}\right)$ who enter the export markets as a consequence of the decrease in $\tau$. The new export sales generate an increase in revenue for all these firms, but only a portion of these firms (with productivity $\varphi>\varphi^{\dagger}$ where $\varphi_{x}^{* \prime}<\varphi^{\dagger}<\varphi_{x}^{*}$ ) also increase their profits. Firms

\footnotetext{
$47 \frac{1+n^{\prime} \tau^{1-\sigma}}{\left(\varphi^{* \prime}\right)^{\sigma-1}}-\frac{1+n \tau^{1-\sigma}}{\left(\varphi^{*}\right)^{\sigma-1}}$ must be positive as $\frac{1+n \tau^{1-\sigma}}{\left(\varphi^{*}\right)^{\sigma-1}}$ increases with $n$.
} 
with productivity levels $\varphi \geq \varphi_{x}^{*}$ who export both before and after the change in $\tau$ enjoy a profit increase that is proportional to their combined revenue increase (their fixed costs do not change) and is increasing in their productivity level $\varphi$ :

$$
\begin{aligned}
\Delta \pi(\varphi) & =\frac{1}{\sigma}\left[r^{\prime}(\varphi)-r(\varphi)\right] \\
& =\varphi^{\sigma-1} f\left[\frac{1+n\left(\tau^{\prime}\right)^{1-\sigma}}{\left(\varphi^{* \prime}\right)^{\sigma-1}}-\frac{1+n \tau^{1-\sigma}}{\left(\varphi^{*}\right)^{\sigma-1}}\right]
\end{aligned}
$$

where the term in the bracket must be positive.

\section{Changes in Aggregate Productivity}

Any productivity average based on (D.2) must increase when $n$ increases or $\tau$ decreases as the new distribution of firm revenues $\frac{r^{\prime}(\varphi) g(\varphi)}{R}$ first order stochastically dominates the old one $\frac{r(\varphi) g(\varphi)}{R}$ : $\int_{o}^{\varphi} r^{\prime}(\xi) g(\xi) d \xi \leq \int_{o}^{\varphi} r(\xi) g(\xi) d \xi \quad \forall \varphi \cdot{ }^{48}$ Note that this property does not hold when $f_{x}$ decreases as the revenues of the most productive firms are not higher with the lower $f_{x}$. Nevertheless, the productivity average $\Phi$ will rise when $f_{x}$ decreases so long as the new exporters are more productive than the average $\left(\varphi_{x}^{*}>\Phi\right)$.

\footnotetext{
${ }^{48}$ Again, this is a direct consequence of the market share re-allocations results.
} 